\title{
Testing for efficiency in the Saudi stock market: does corporate governance change matter?
}

\author{
Mamdouh Abdulaziz Saleh Al-Faryan ${ }^{1,2,3}$ (D) Everton Dockery ${ }^{1}$
}

Accepted: 30 September 2020 / Published online: 27 October 2020

(c) The Author(s) 2020

\begin{abstract}
We study the informational efficiency of the Saudi stock market (SSM), while accounting for corporate governance change, based on single, multiple, and variance ratio-based WALD tests and runs test. The main findings indicate that when the whole period is considered, the random walk hypothesis is rejected, but when divided into two sub-periods separated by the pre-corporate governance and the period marked by corporate governance change, the analysis demonstrates sub-period improvement in weak-form efficiency for the examined series. Robustness of results is verified by analysis using sector indices, which point to market efficiency. Interestingly, Hurst Exponent estimates evidence long-range dependence which suggests the predictability of stock prices and the prospect of speculative opportunities.
\end{abstract}

Keywords Saudi stock market - Corporate governance $\cdot$ Market efficiency $\cdot$ Random walk . Variance ratio $\cdot$ Hurst exponent

JEL Classification $\mathrm{G} 14 \cdot \mathrm{G} 15 \cdot \mathrm{G} 34$

\section{Introduction}

How efficient are the world's stock markets? This question has continued to elicit the interest of researchers ever since the work of Samuelson (1965) and the persuasive treatise of Fama (1965, 1970, 1991); see, for example, Lo and MacKinlay (1988); Poterba and Summers (1988); Shiller (1989); Urrutia (1995); Kavussanos and Dockery (2001); Al-Khazali et al. (2007); Kim and Shamsuddin (2008); Wang et al. (2009); Borges (2010); Rejichi and Aloui (2012); Sensoy (2013); Gozbasi et al. (2014); Tiwari and Kyophilavong (2014); Metghalchi et al. (2015), Anagnostidis et al. (2016), and Seetharam et al. (2017). Fama's (1991) narrative on the categories of market efficiency has triggered a considerable amount

Mamdouh Abdulaziz Saleh Al-Faryan

Al-Faryan@hotmail.com

1 Department of Economics and Finance, Faculty of Business and Law, University of Portsmouth, Richmond Building Portland Street, Portsmouth P01 3DE, UK

2 The Saudi Economic Association, Riyadh, Saudi Arabia

3 Consultant in Economics and Finance, Riyadh, Saudi Arabia 
of empirical research that seeks to determine whether developed and nascent capital markets reveal themselves to be specifically weak-form or semi-strong-form efficient capital markets; for a discussion, see Lim and Brooks (2011). This paper seeks to extend our understanding and build on the mentioned literature by analysing the efficiency of the Saudi stock market (SSM) and, in doing so, identify whether the changes in corporate governance following the stock market crash of 2006 improved SSM efficiency. If such changes do have some influence, it can be inferred that corporate governance mechanisms have improved the timely release of information and contributed favourably to the timeliness of price discovery and gradual improvement of the SSM's efficiency. Prior studies on the SSM's efficiency have tended to include this market as part of a sample of emerging stock markets or as part of a group of Gulf Cooperation Council (GCC) stock markets; see, for example, Butler and Malaikah (1992); Abraham et al. (2002); Al-Khazali et al. (2007); and Al-Ajmi and Kim (2012). In their study of the Kuwaiti and Saudi stock markets, Butler and Malaikah (1992) find that stocks traded on these markets do not support the random walk hypothesis (RWH), while Al-Khazali et al. (2007) report that stocks traded on the SSM do not obey the RWH, as is also the case with other GCC markets. To date, few studies have focussed solely on the SSM.

Examination of the SSM is important for the following reasons. First, the SSM is the largest and most well-known stock market in the GCC. Moreover, in view of ongoing economic reforms and restructuring of the Saudi economy, the projected performance of the economy and the stock market are likely to attract institutional investors and portfolio managers who wish to attain diversification benefits from investing in Saudi stocks and thereby reduce systematic risk. Therefore, it is of interest to learn how efficient the SSM is, particularly in view of the developments related to corporate governance, interest shown by international investors, and implications for the potential misallocation of resources. Therefore, the question we seek to address directly relates to whether developments and improvements in the institutional arrangement of the stock market have enhanced the SSM such that the market is weak-form efficient. Second, in consideration of policymakers' efforts to establish a framework of corporate governance, it is of some interest to assess whether the imposition of the 2006 corporate governance codes influenced the SSM's institutional arrangement and overall efficiency or generally influenced the SSM. Thus, understanding the efficiency of the SSM would be of considerable benefit to policymakers' decision making if it informs them to avoid areas of resource misallocation that would otherwise have a negative impact on long-term economic growth. Moreover, improving the efficiency of the resource allocation route would perhaps mitigate distortions in the economy.

This study applies five empirical methodologies-single, multiple, and variance-ratiobased WALD tests, runs tests, and Hurst exponents - to investigate whether the RWH holds for the SSM. The analysis differs from previous studies on the SSM primarily due to the use of a new and expanded dataset that covers the pre- and post-corporate governance improvement periods (when efforts were made by policymakers to regulate information disclosure, shareholder protection, enforcement, and governance codes, etc.). Thus, consideration of various measures to improve the development, regulation, and transparency of the SSM is regarded as an important component of the newly created framework.

The paper proceeds as follows. In Sect. 2 we provide a select review of the related literature and develop our hypothesis. This is followed by a discussion in Sect. 3 of the empirical methods on which the analysis is conducted to study the random walk behaviour of stocks traded on the SSM. In Sect. 4 we discuss the data and descriptive statistics. Section 5 presents the results of the econometric analysis of the data and discusses those results. Section 6 concludes the paper. 


\section{Related literature and hypothesis development}

Numerous articles have examined the efficiency of the world's stock markets. The empirical evidence reports mixed results, either finding evidence to reject the RWH (Summers 1986; Lo and MacKinlay, 1988; Ayadi and Pyun (1994); Urrutia (1995); Grieb and Reyes (1999); and Karemera et al. (1999); Darrat and Zhong, 2000; Narayan, 2008; Hasanov, 2009; Tiwari and Kyophilavong, 2014) or to conclude that stock price behaviour agrees with the efficient market hypothesis (Shiller 1989; Tabak 2003; Narayan 2005; Narayan and Smyth 2005; Qian et al. 2008; Alexeev and Tapon 2011; Gozbasi et al. 2014). Of the referenced studies, Poterba and Summers (1988) argue that there is limited theoretical ground supporting the null hypothesis that stock prices follow a random walk. In contrast, Lo and MacKinlay (1988), in applying a more cogent volatility-based measure established on the assumptions of homoscedasticity and heteroscedasticity, reject the RWH for the stock return series of the NYSE and AMEX. This work has triggered innumerable studies testing the RWH. Ayadi and Pyun (1994) used the variance ratio test to examine RWH for the Korean stock market. They found that, while the RWH was rejected under the assumption of homoscedasticity, when the heteroscedastic stochastic disturbance term was considered, the RWH was confirmed. Urrutia (1995), Grieb and Reyes (1999), and Karemera et al. (1999) studied the RWH for a selection of emerging equity markets, while Darrat and Zhong (2000) examined the RWH for the Shanghai and Shenzhen stock exchanges. Generally, these studies refute the RWH for the stock markets examined. Most recently, Gozbasi et al. (2014) applied the nonlinear unit root test to daily Turkish stock market prices and three sector indices and found evidence in support of weak-form efficiency. Tiwari and Kyophilavong (2014) used both the wavelet-based unit root test and unit root test that incorporate/exclude structural breaks in the data to study the RWH for BRIC (Brazil, Russia, India, and China) stock indices. The reported results show that the RWH is rejected for all BRIC countries, except for the Russian stock market. Seetharam et al. (2017) examined the RWH for the South African stock market using both equity and sector indices, and for several data frequencies. Their results show that, using daily data, $86 \%$ of the shares and indices support the RWH, while using weekly, monthly, quarterly, and semi-annual data, the figures for support are $78 \%, 56 \%, 22 \%$, and $24 \%$, respectively. The authors conclude that market efficiency, in relation to the efficient market hypothesis (EMH), is highly dependent on data frequency as well as the sample of assets employed.

A segment of the existing literature focuses on documenting the efficiency of GCC stock markets. For instance, Squalli (2006) employs runs and variance ratio tests to examine the EMH for the daily composite and sector indices of the Abu Dhabi and Dubai stock markets. Their findings show that while the variance ratio tests reject the RWH for all sectors of the Dubai market under the assumption of homoscedasticity, when the assumption of heteroscedasticity is used, the RWH is accepted but only for the banking sector of Dubai. However, the runs test could only evidence efficiency for the insurance sector of the Dubai market. Al-Khazali et al. (2007) examined the RWH for eight stock markets using weekly data. They applied both the runs test and Wright's (2000) nonparametric single variance ratio test to provide insights into the informational efficiency of the markets. However, although their results under both measures do not support the RWH, when correcting for thin trading their results did not reject the RWH. Smith (2007) examined the weak-form efficiency of five stock markets by applying the MVR test of Chow and Denning (1993). The results reveal that while the RWH is not rejected for the markets of Israel, Jordan, and Lebanon, it was rejected for the Kuwait and Oman stock markets. Recently, Al-Shboul and 
Alsharari (2019) studied the dynamic behaviour of evolving efficiency in the United Arab Emirates (UAE) stock market and report evidence of evolving efficiency for the Dubai Financial Market (DFM) and the Abu Dhabi Stock Exchange (ADSE). They also note that although the markets reveal evolving efficiency, there are features of long-range dependence, which indicate that the UAE stock markets are inefficient while also trending towards weak-form efficiency.

Rejichi and Aloui (2012) applied the Hurst exponent to examine the efficiency of 11 Middle East and North African (MENA) markets. The authors show that while MENA stock markets have long-range dependence, certain markets became more efficient, except those of Israel, Turkey, Egypt, Iran, and Saudi Arabia. Using a time-varying generalised Hurst exponent approach, Sensoy (2013) studied the efficiency of 15 MENA stock markets and found that all MENA markets display various levels of long-range dependence over time, and moreover, that the Arab spring had a negative impact on the efficiency of the markets. The study reports the Turkish and Israeli stock markets to be the most efficient, displaying characteristics of developed financial markets.

Taking into account the insights from the empirical literature and the nature of the Saudi market, this study considers the implementation of the 2006 Saudi corporate governance codes to investigate whether it might have an exogenous impact on the SSM. Hence, we hypothesise the following:

Hypothesis 1 (H1) The 2006 corporate governance codes have a positive impact on the institutional arrangements and, thus, on the efficiency of the SSM.

This hypothesis is consistent with the broad aims of Saudi Arabia's corporate governance code to impose relevant rules for good and responsible governance - including internal control systems and procedures - which publicly listed corporations would be pressured by the Capital Market Authority (CMA) to adopt. This extends to approved policies and procedures used to regulate the behaviour of traders and management, with the ultimate objective of facilitating SSM's transition towards more efficient market operation, while considering investor protection. In the finance literature, this is the type of impact that compliance with a country's corporate governance code is expected to have on publicly traded corporations (see Stiles and Taylor 1993, Dedman 2002, Aguilera and CuervoCazurra 2004, Fernández-Rodríguez et al. 2004, and Zattoni and Cuomo 2008). Nonetheless, given that the SSM can be considered an informationally inefficient market wherein policymakers, prior to the 2006 SSM crash, have been slow to implement much needed regulatory changes, we hypothesise the following:

Hypothesis 2 (H2) : Before 2006, the SSM did not conform to the RWH, and thus, information was not immediately reflected in the prices of traded stocks.

Therefore, we do not expect the SSM to behave a priori in accordance with the predictions of the EMH. However, Hinich and Serletis (2007) argue that when unexpected shocks, such as a stock market crash, hit the market, it takes longer for investors to determine the full impact of the news before settling at a new equilibrium level. Therefore, given that the emerging and largely inefficient SSM was adversely affected by the 2006 stock market shock, which was seen by the market and investors as a reflection of the Saudi policymakers' failure to address long-standing inherent market weaknesses, it is highly unlikely that the SSM can evolve from a chaotic market environment, where investors overreact to both 
domestic and global news, into an efficient stock market within a relatively short period. This is because the stock market crash of 2006 might also be attributed to market inefficiency, which, as Fortune (1991) notes, provided an opportunity for policymaker intervention in order to arrest prevailing market failures. On this issue, Antoniou et al. (1997) suggest that understanding the nature of market inefficiency determinants would help ascertain the appropriate regulatory framework necessary for establishing an efficiently functioning stock market. Therefore, investigating the above hypotheses would fill a void in the literature, not only in terms of extending the evidence of previous studies on SSM efficiency but also with respect to the relevance of corporate governance changes for market efficiency.

\section{Methodology}

Five tests are implemented to analyse the RWH for the return series of the SSM. The first test employed is the single $V R$ test of Lo and MacKinlay (1988). The starting point of this test argues that if a time series, denoted by $P_{t}$, is a pure random walk, as explicitly given by

$$
P_{t}=P_{t-1}+\varepsilon_{t}
$$

then the variance of its $k$-differences will grow linearly with the magnitude of $k$. This suggests that, for a random walk series, the variance of its $k$-difference will be $k$ times the variance of its first difference. Hence, if $(n k+1)$ observations of $\left(P_{0}, P_{1}, P_{2}, \ldots, P_{n k}\right)$ at equally spaced intervals (where $k$ is an integer greater than 1) are obtained, the ratio of one $k$ th of the variance of $P_{t}-P_{t-k}$ to the variance of $P_{t}-P_{t-1}$ would be equal to unity. The $V R$ is computed as:

$$
V R(k)=\frac{\sigma^{2}(k)}{\sigma^{2}(1)},
$$

where $\sigma^{2}(k)$ is the unbiased estimator of $1 / k$ of the variance of the $k$ th difference of the logged stock return, $P_{t}-P_{t-k}$, and $\sigma^{2}(1)$ is an unbiased estimator of the variance of the logged return $\left(P_{t}-P_{t-1}\right)$. The related standard $\mathrm{Z}$ test statistic under the assumption of homoscedasticity, $\mathrm{Z}(k)$ is

$$
Z(k)=\frac{V R(k)-1}{[\Phi(k)]^{\frac{1}{2}}} \stackrel{a}{\rightarrow} N(0,1),
$$

where the $V R$ statistic can be standardised asymptotically to a standard normal test statistic, and the test under the assumption of heteroscedasticity is:

$$
Z^{*}(k)=\frac{V R(k)-1}{\left[\Phi^{*}(k)\right]^{\frac{1}{2}}} \stackrel{a}{\rightarrow} N(0,1),
$$

where $\Phi^{*}(k)$ is the asymptotic variance of the $V R$ that is consistent with the null hypothesis, $H_{0}^{*}$, of heteroscedasticity. Under the null hypothesis of a Gaussian random walk, estimators $\sigma^{2}(k)$ and $\sigma^{2}(1)$ should be close in value. A random walk test is then performed by equating the juxtaposition of the difference between the two estimators to zero. The test is commensurate to testing the null hypothesis that $V R(k)=1$, meaning that the stock price series follows a random walk, against an alternative hypothesis that $V R(k) \neq 1$. 
The second test is the MVR test of Chow and Denning (1993), which overcomes limitations associated with Lo and MacKinlay's (1988) VR test of the necessity to test the individual $V R$ every time for a single sum total interval, $k$. This means that they are effectively individual testable hypotheses as they entertain multiple interval testing. ${ }^{1}$ Chow and Denning's (1993) MVR test is expressed as follows:

$$
P R\left[\max \left(\left|Z\left(k_{1}\right)\right|, \ldots,\left|Z\left(k_{m}\right)\right|\right) \leq S M M(\alpha ; m ; T)\right] \geq 1-\alpha,
$$

where $\operatorname{SMM}(\alpha ; m ; T)$ is the upper $\alpha$ point of the studentised maximum modulus (SMM) distribution with parameter $m$ and $T$ (sample size) degrees of freedom. Asymptotically, when $T$ is boundless or $\infty$

$$
\operatorname{SMM}(\alpha ; m ; \infty)=Z_{\alpha * / 2}
$$

where

$$
a^{*}=1-(1-\alpha)^{1 / m}
$$

Using multiple $k \mathrm{~s}$, the null hypothesis would be accepted only if it is not rejected for all $k$ values. If the maximum absolute value of $Z\left(k_{i}\right)$ or $Z *\left(k_{i}\right)$ is greater than the SMM critical value, the RWH is rejected.

The third test is the joint $V R$ test proposed by Richardson and Smith (1991), which makes use of the serial correlation among $V R s$ when the observations used to calculate the $V R s$ overlap. Therefore, given a set number of $m V R s$ with different return horizons, to test for the null hypothesis, it is necessary to explicitly consider the serial correlation among the $m$ variance ratios. It follows that, for an $m \times 1$ vector of variance ratios given by

$$
V_{m}=\left[V_{r}\left(k_{1}\right), \ldots, V_{r}\left(k_{m}\right)\right]^{\prime},
$$

the joint hypothesis is $H_{03}: V_{r}\left(k_{i}\right)=0$, where $i=1, \ldots, m$, which can be examined by the WALD statistic:

$$
R S(k)=T\left(V R-1_{m}\right)^{\prime} \Phi^{-1}\left(V R-1_{m}\right),
$$

where $V R$ is the $(m \times 1)$ vector of sample $k V R s, 1_{m}$ is the $(m \times 1)$ unit vector, and $\Phi$ is the covariance matrix of $V R_{m}$. Under the null hypothesis, the joint statistic follows an $\chi^{2}$ distribution with $k$ degrees of freedom.

The fourth test applied is the non-parametric runs test which also studies the randomness of the stock returns series. Here, and assuming the latter is random, the actual number of runs in the series should be adjacent to the expected number of runs regardless of signs (positive [+] every time the return is above the mean return, zero [0], or negative [-] if it is below the mean return). Under the hypothesis of independence, the expected number of runs $(M)$ may be estimated by the following equation:

$$
E(M)=\frac{\left[N(N+1)-\sum_{j=1}^{3} n_{j}^{2}\right]}{N},
$$

\footnotetext{
1 Chow and Denning (1993) demonstrate the asymptotic joint confidence interval of at least $100(1-\alpha) \%$ for a set of $m$ variance ratios $V R\left(k_{i}\right), i=1,2, \ldots m$.
} 
where $N$ is the total number of observations of stock returns, and $n_{j}$ is the total number of runs or price changes of each type (i.e. from the same category), with $j=1,2,3$ representing the total number of positive $(+)$, negative $(-)$, and zero $(0)$ stock price changes. The variance of $M$ is

$$
\sigma_{M}^{2}=\frac{\sum_{j=1}^{3} n_{j}^{2}\left[\sum_{j=1}^{3} n_{j}^{2}+N(N+1)\right]-2 N \sum_{j=1}^{3} n_{j}^{3}-N^{3}}{N^{2}(N-1)} .
$$

For a large $N$, the sampling distribution of $M$ is approximately normal. The standardised variable may be determined as follows:

$$
Z=\frac{M-E(M)}{\sigma_{M}},
$$

where $M$ is the actual number of observed runs. If the $z$-value is greater than the critical values, we denounce the null hypothesis of independence of the stock return series. Otherwise, we conclude that the returns are independent.

\subsection{Hurst Exponent approach}

To confirm the results obtained from the foregoing tests, we apply the Hurst exponent calculated by the rescaled range, $\mathrm{R} / \mathrm{S}$, which is deemed to be a more elegant form of the variance ratio test. Zunino et al. (2009) contend that the exponent measures the long-range dependence in stock market indices, where an autocorrelation exists between distant observations will imply market inefficiency. The R/S statistic is the range of partial sums of deviations of the return series from its mean, rescaled by the standard deviation. The R/S statistic is represented as:

$$
(R / S)=\frac{1}{S_{\tau}}\left[\max _{1 \leq t \leq \tau} \sum_{t=1}^{\tau}\left(r(t)-\bar{r}_{\tau}\right)-\min _{1 \leq t \leq \tau} \sum_{t=1}^{\tau}\left(r(t)-\bar{r}_{\tau}\right)\right],
$$

where $\bar{r}_{\tau}$ is the sample mean of the return series and $s_{\tau}$ is the standard deviation estimator

$$
s_{\tau}=\left[\frac{1}{\tau} \sum_{t}\left(r(t)-\bar{r}_{\tau}\right)^{2}\right]^{1 / 2}
$$

Peters (1994) notes that Hurst has shown R/S to be described as:

$$
(r / s)_{\tau}=\left(\frac{\tau}{2}\right)^{H}
$$

We are mindful that the EMH instructs that market prices obey a random walk and are therefore unpredictable. In keeping with this understanding, in cases where the return series are characterised by Hurst components ranging between 0 and 1, and with an exponent $\mathrm{H}=0.5$ this would imply a random walk - meaning a random process without long memory where accretions are independent and identically normally distributed, pursuant to the EMH (Peters 1994). Notably, series presenting Hurst exponents different from 0.5 also display long memory and their accretions are not independent, thereby making the series predictable and thus possibly offering speculative profitable opportunities. Values of 
Table 1 Preliminary statistics on Saudi stock market returns

\begin{tabular}{lrrc}
\hline & \multicolumn{1}{l}{ Daily } & \multicolumn{1}{l}{ Weekly } & \multicolumn{1}{l}{ Monthly } \\
\hline Mean & 0.000309 & 0.001756 & 0.007753 \\
Median & 0.000696 & 0.003461 & 0.011405 \\
Maximum & 0.098458 & 0.147541 & 0.195963 \\
Minimum & -0.098130 & -0.228196 & -0.0257516 \\
Standard deviation & 0.012847 & 0.031746 & 0.067301 \\
Skewness & -0.692368 & -0.886506 & -0.0389769 \\
Kurtosis & 15.15046 & 9.374735 & 4.375653 \\
Jarque-Bera & $39232.25 * * *$ & $2088.710 * * *$ & $28.54281 * * *$ \\
\hline
\end{tabular}

The sample period covers 1994-2016 with the daily frequency totalling 6296, the weekly frequency 1145, and the monthly frequency 274 . In addition to the mean, the standard deviation, minimum, maximum, skewness, and kurtosis statistics, the table reports the Jarque-Bera normality test. The asterisks $* * *$ represent significance at the 0.01 level

$\mathrm{H}$ ranging from 0.5 to 1 simply evidence an enduring trend-reinforcing series, and imply positive long-range dependence. However, values ranging from 0 to 0.5 suggest anti-persistence, and therefore, point to the tendency of past trends of a series reversal in the future, thus expressing negative long-range dependence.

\section{Data}

The dataset analysed in this study comprises the stock market's daily, weekly, and monthly Tadawul All-Share Index prices. The daily return series spans 1 February 1994 to 28 December 2016, while the weekly series covers the period from 2 February 1994 to 28 December 2016, and the monthly series runs from the end of February 1994 to the end of December 2016. This was the longest period of available price data at the time of the data collection, covering the periods before and after the implementation of the Saudi corporate governance code. The return series, $R_{t}$, are obtained by calculating the first logarithmic difference of the stock market price, $P_{t}$, with $R_{t}=\left[\ln \left(P_{t}\right)-\ln \left(P_{t-1}\right)\right] \times 100$ for each time series, where $P_{t}$ and $P_{t-1}$ are the stock prices at time t and t -1 , respectively.

We apply the empirical tests to the entire 23-year sample period (1994-2016), and to account for corporate governance reforms directed at increasing the transparency and efficiency of the SSM, the whole period of stock price series are divided into two sub-periods: the pre-governance code period from 1 February 1994 to 27 December 2006, and the post-governance code period from 6 January 2007 to 28 December 2016. Testing the EMH over different periods has the benefit of allowing for structural changes in the return series, which holds the possibility of the EMH being rejected in one time period while accepted in others. The same time period is used for both the weekly and monthly analyses. We use these data frequencies to overcome issues such as bias due to daily data (e.g. nontrading, bid-ask spread, and synchronous prices) and assumptions about weekly (alternate day prices in the case of non-trading on the day of the week observed) and monthly data. This is because, according to Lo and MacKinlay (1988), randomness tends to be present in monthly rather than daily data, as the white noise of daily data is more likely to result in autocorrelation. 
The statistical characteristics of daily, weekly, and monthly returns of the SSM are shown in Table 1 (Appendix "1A"). The return series may be described as having positive mean returns, while also showing minimum returns $-0.098130,-0.228196$, and -0.0257516 , respectively, and a maximum of $0.098458,0.147541$, and 0.195963 , respectively. At the same time, the market exhibits a high level of variability as measured by the standard deviation of returns.

The returns also show that the distributions of stock price changes evidence excess skewness and kurtosis, indicating that each return has typical characteristics of leptokurtosis and fat tails. It is well established that leptokurtosis and fat tails are common characteristics of financial time series. Moreover, the Jarque-Bera statistic is significant from zero, indicating that none of the returns follow a normal distribution. Also, the Shapiro-Wilk test suggests that the return series do not obey the normal distribution. To establish that we are dealing with nonstationary time series, we first ascertain whether the returns are stationary. For this exercise, unit root (augmented Dickey and Fuller 1979 and Phillips and Perron 1988) and stationarity (Kwiatkowski et al. 1992) tests are applied. Since these tests are well known, we will not explain them here, except to note that the results are reported in Table 1 (Appendix “1B"), and are all significant from zero indicating that all returns contain a unit root. Therefore, based on the summary statistics, all returns are not normally distributed and, moreover, all are stationary.

In addition, the Broock et al. (1996) BDS test is employed to accommodate the possibility of nonlinear predictability in the return series. Table 2 displays the results of the BDS test for embedding dimensions $(m)$ from 2 to 10 and metric bound $(\varepsilon)$ equals 0.7 times the standard deviation $(\sigma)$ of the SSM return series. The results clearly indicate that the Independent and Identically Distributed (IID) null is too restrictive for the data series used in this study. As a result, the IID tests are not appropriate for testing conditional mean predictability for reason that it detects serial dependence in every conditional moment, and may lead to an incorrect refusal of the EMH when the data series are conditionally heteroscedastic.

Next, we use the unit root test to examine the extent of structural breaks in the return series under study. The structural break unit root test results for the return series are presented in Table 3. The results of this test show that the null of a unit root is not rejected at the $1 \%, 5 \%$, and $10 \%$ significance levels, and that the break dates were themselves significant in the sense that they confirm important events that occurred in Saudi Arabia (both weekly and monthly returns). This had a decided impact on the SSM, such as the Saudi stock market crash and the implementation of corporate governance provisions in 2006 associated with the period of corporate governance change. The second important break captured corresponds to the impact of the 2008 global banking and financial crisis on the Saudi economy and the SSM more generally.

Figure 1 shows the time-series plot of the daily returns of stock price series. The range fluctuation of the return series is non-constant, which means the variance of returns changes over time. Most notably, the SSM was extremely volatile around the stock market crash of 2006, which ended the rapid expansion in the stock market, and during the financial crisis of 2007-2008, which led to a succession of extremely large positive and negative returns within a short-term horizon. This was mainly due to the global economic recession that followed the financial crisis, combined with the expectations of economic agents of a sustained oil slump, which culminated in stagnated growth against the backdrop of falling oil prices and oil revenue upon which the Saudi government relies. The market also experienced some highly volatile periods, such as in 2006, 2008-2011, and 2014-2015, with the latter period marked by the oil price shock of 2014 and subsequent fluctuating oil prices 
Table 2 BDS test results for the return series of the SSM

\begin{tabular}{|c|c|c|c|c|}
\hline Returns & $m$ & Daily & Weekly & Monthly \\
\hline \multicolumn{5}{|l|}{$\frac{\varepsilon}{\sigma}=0.7$} \\
\hline \multirow[t]{9}{*}{ Panel A: 1994-2016 } & 2 & $0.204462 * * *$ & $0.197776^{* * * *}$ & 0.182507 *** \\
\hline & 3 & $0.347992 * * *$ & $0.336172 * * *$ & $0.310540 * * *$ \\
\hline & 4 & $0.448521 * * *$ & $0.431763 * * *$ & $0.397294 * * *$ \\
\hline & 5 & $0.518684 * * *$ & $0.497287 * * *$ & $0.454042 * * *$ \\
\hline & 6 & $0.567515^{* * *}$ & $0.541808 * * *$ & $0.489413 * * *$ \\
\hline & 7 & $0.601389 * * *$ & $0.571825^{* * *}$ & $0.509430 * * *$ \\
\hline & 8 & $0.624738 * * *$ & $0.591639 * * *$ & $0.518891 * * *$ \\
\hline & 9 & $0.640720 * * *$ & $0.604085^{* * *}$ & $0.521512 * * *$ \\
\hline & 10 & 0.651511 *** & $0.611331 * * *$ & $0.519226 * * *$ \\
\hline \multirow[t]{9}{*}{ Panel B: 1994-2006 } & 2 & $0.206733 * * *$ & $0.203271^{* * *}$ & $0.192985 * * *$ \\
\hline & 3 & $0.352115^{* * *}$ & $0.345309 * * *$ & $0.343370 * * *$ \\
\hline & 4 & $0.454280 * * *$ & $0.444703 * * *$ & $0.411955 * * *$ \\
\hline & 5 & $0.526067 * * *$ & $0.514452 * * *$ & $0.472831 * * *$ \\
\hline & 6 & $0.576483^{* * *} *$ & $0.563496 * * *$ & $0.515344 * * *$ \\
\hline & 7 & $0.611869 * * *$ & $0.597993 * * *$ & $0.545235 * * *$ \\
\hline & 8 & $0.636683 * * *$ & $0.622244 * * *$ & $0.566460 * * *$ \\
\hline & 9 & $0.654049 * * *$ & $0.639321 * * *$ & $0.581570 * * *$ \\
\hline & 10 & $0.666176^{* * *}$ & $0.651369 * * *$ & $0.592234 * * *$ \\
\hline \multirow[t]{9}{*}{ Panel C: 2007-2016 } & 2 & $0.198865^{* * *}$ & $0.182521 * * *$ & $0.150417 * * *$ \\
\hline & 3 & $0.337809 * * *$ & $0.309154 * * *$ & $0.255709 * * *$ \\
\hline & 4 & $0.434171 * * *$ & $0.394510 * * *$ & $0.318837 * * *$ \\
\hline & 5 & $0.500476^{* * *}$ & $0.450399 * * *$ & $0.352347 * * *$ \\
\hline & 6 & $0.545673 * * *$ & $0.485798 * * *$ & $0.368168 * * *$ \\
\hline & 7 & $0.576142 * * *$ & $0.506666^{* * *}$ & $0.372387 * * *$ \\
\hline & 8 & $0.596181 * * *$ & $0.517687 * * *$ & $0.366856^{* * *}$ \\
\hline & 9 & $0.608969 * * *$ & $0.521732 * * *$ & $0.356002 * * *$ \\
\hline & 10 & $0.616713 * * *$ & $0.521935 * * *$ & $0.342110 * * *$ \\
\hline
\end{tabular}

The BDS statistics are distributed as a normal variable under the hypothesis of IID; see Broock et al. (1996). We used fraction of pairs: $\varepsilon$ is calculated to ensure a certain fraction of the total number of pairs of points in the sample lie within $\varepsilon$ of each other. *** represents significance at the 0.01 level

Table 3 Unit root test with structural breaks

\begin{tabular}{llllll}
\hline Series & \multicolumn{2}{l}{ Level } & & & \multicolumn{2}{l}{ First difference } \\
\cline { 2 - 3 } \cline { 5 - 6 } & ADF & Break date & & ADF & Break date \\
\hline Daily & -3.2305 & $12 / \mathrm{Jan} / 2008$ & & $-71.8393 * * *$ & $27 / \mathrm{March} / 1994$ \\
Weekly & -3.1591 & $19 / \mathrm{March} / 2003$ & & $-30.4439 * * *$ & $10 / \mathrm{May} / 2006$ \\
Monthly & -3.6385 & June/2006 & & $-16.4986 * * *$ & April/2006
\end{tabular}

Test allows for a constant and a liner; one-sided (lower-tail) test of the null hypothesis that the variable has a unit root; $1 \%, 5 \%$, and $10 \%$ significance critical values equal $-5.3476,-4.8598$, and -4.6073 , respectively 


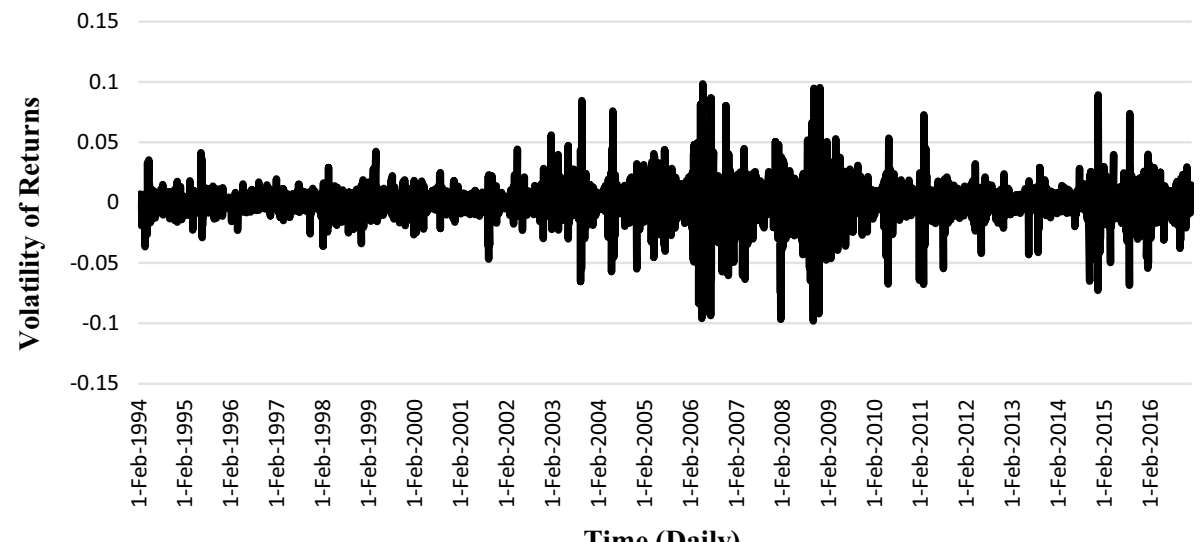

Fig. 1 Daily returns of the Saudi stock market index (1994-2016)

and tightening oil revenues. To help bridge the gap in the budget shortfall, as well as to buttress the finances affected by the fall in oil revenue, the Saudi government raised USD 17.5 billion through a sovereign bond sale, which is one of the largest fixed income offerings for an emerging market to date. In Fig. 1, volatility clustering is evident for the return series, indicating the presence of heteroscedasticity.

\section{Empirical analysis}

\subsection{Principal findings}

Using the methods described earlier, we assess the weak-form efficient market hypothesis by testing the RWH. To perform the variance ratio test of a random walk, we calculate the $V R s$ and $V R(k)$ for the homoscedastic $Z(k)$ and heteroscedastic $Z^{*}(k)$ cases for each $k=2$, 4,8 , and 16. To ensure the SSM follows the RWH and accepts the null hypothesis of a random walk, and thus the weak-form version of the efficient market hypothesis, the variance ratio test should be equal to unity to refute the presence of autocorrelation between intervals. In other words, the ratio of $1 / k$ times the variance of the $k$-differences over the variance of the first differences should be equal to unity. If the results show that $\operatorname{VR}(k)>1$ or $V R(k)<1$, then a positive or negative autocorrelation would strongly suggest that opportunities to predict future price changes exist. Further, if such potential for exploiting market prices were present, it would provide sufficient grounds for refuting the RWH for the SSM, thereby rejecting the weak-form efficiency of the market.

The empirical analysis commences with the daily returns data, followed by the weekly observed returns, and then the monthly observed returns. The results from applying both $V R$ statistics with homoscedastic and heteroscedastic error terms, respectively denoted by $Z(k)$ and $Z^{*}(k)$, of the stock return series at different intervals $(2,4,8$, and 16) are presented in Table 4. The individual $V R s, V R(k)$, are reported in the main rows, and the Z-statistics are given immediately below. For the daily observed stock return series reported in Panel A for the entire sample period of 1994-2016, the values indicate that we can reject the RWH for all sample intervals of $k$. The evidence suggests that both autocorrelation and 
Table 4 Variance ratios for daily, weekly, and monthly returns

\begin{tabular}{|c|c|c|c|c|c|}
\hline & & \multicolumn{4}{|c|}{ Sampling intervals $(k)$} \\
\hline & & 2 & 4 & 8 & 16 \\
\hline \multicolumn{6}{|c|}{ Panel A: 1994-2016 } \\
\hline \multirow[t]{3}{*}{ Daily } & $\operatorname{VR}(k)$ & 1.09 & 1.13 & 1.22 & 1.30 \\
\hline & $\mathrm{Z}(k)$ & $7.07 * * *$ & $5.33 * * *$ & $5.83 * * *$ & $5.47 * * *$ \\
\hline & $\mathrm{Z}^{*}(k)$ & $3.23 * * *$ & $2.36^{* *}$ & $2.58 * * *$ & $2.50 * *$ \\
\hline \multirow[t]{3}{*}{ Weekly } & $\operatorname{VR}(k)$ & 1.12 & 1.23 & 1.34 & 1.53 \\
\hline & $\mathrm{Z}(k)$ & $3.92 * * *$ & $4.17 * * *$ & $3.85 * * *$ & $4.06 * * *$ \\
\hline & $\mathrm{Z}^{*}(k)$ & $2.11 * *$ & $2.34 * *$ & $2.19 * *$ & $2.44 * *$ \\
\hline \multirow[t]{3}{*}{ Monthly } & $\operatorname{VR}(k)$ & 1.20 & 1.40 & 1.75 & 1.99 \\
\hline & $\mathrm{Z}(k)$ & $3.23 * * *$ & $3.57 * * *$ & $4.21 * * *$ & $3.74 * * *$ \\
\hline & $\mathrm{Z}^{*}(k)$ & $2.11 * *$ & $2.51 * *$ & $3.15 * * *$ & $2.90 * * *$ \\
\hline \multicolumn{6}{|c|}{ Panel B: 1994-2006 } \\
\hline \multirow[t]{3}{*}{ Daily } & $\operatorname{VR}(k)$ & 1.08 & 1.06 & 1.19 & 1.32 \\
\hline & $\mathrm{Z}(k)$ & $5.05 * * *$ & $2.05 * *$ & $4.01 * * *$ & $4.44 * * *$ \\
\hline & $\mathrm{Z}^{*}(k)$ & $2.03 * *$ & 0.80 & 1.56 & $1.78^{*}$ \\
\hline \multirow[t]{3}{*}{ Weekly } & $\operatorname{VR}(k)$ & 1.23 & 1.38 & 1.53 & 1.83 \\
\hline & $\mathrm{Z}(k)$ & $5.77 * * *$ & $5.19 * * *$ & $4.56^{* * *}$ & $4.81 * * *$ \\
\hline & $\mathrm{Z}^{*}(k)$ & $2.96^{* * *}$ & $2.79 * * *$ & $2.39 * *$ & $2.63 * * *$ \\
\hline \multirow[t]{3}{*}{ Monthly } & $\operatorname{VR}(k)$ & 1.27 & 1.57 & 2.13 & 2.59 \\
\hline & $\mathrm{Z}(k)$ & $3.36 * * *$ & $3.75 * * *$ & $4.74 * * *$ & $4.47 * * *$ \\
\hline & $\mathrm{Z}^{*}(k)$ & $2.14 * *$ & $2.49 * *$ & $3.29 * * *$ & $3.37 * * *$ \\
\hline \multicolumn{6}{|c|}{ Panel C: 2007-2016 } \\
\hline \multirow[t]{3}{*}{ Daily } & $\operatorname{VR}(k)$ & 1.10 & 1.19 & 1.24 & 1.27 \\
\hline & $\mathrm{Z}(k)$ & $4.77 * * *$ & $5.03 * * *$ & $3.98 * * *$ & $3.09 * * *$ \\
\hline & $\mathrm{Z}^{*}(k)$ & $2.53 * *$ & $2.57 * *$ & $2.06^{* *}$ & $1.66^{*}$ \\
\hline \multirow[t]{3}{*}{ Weekly } & $\operatorname{VR}(k)$ & 1.01 & 1.09 & 1.15 & 1.15 \\
\hline & $\mathrm{Z}(k)$ & 0.31 & 1.04 & 1.12 & 0.78 \\
\hline & $\mathrm{Z}^{*}(k)$ & 0.18 & 0.62 & 0.69 & 0.52 \\
\hline \multirow[t]{3}{*}{ Monthly } & $\operatorname{VR}(k)$ & 1.12 & 1.16 & 1.20 & 0.89 \\
\hline & $\mathrm{Z}(k)$ & 1.32 & 0.94 & 0.74 & -0.28 \\
\hline & $\mathrm{Z}^{*}(k)$ & 0.90 & 0.72 & 0.63 & -0.25 \\
\hline
\end{tabular}

The tests are based on the variance ratio (VR) test if the ratio of the variance of the $k$ th difference scaled by $k$ to the variance of the first difference tends to equal unity. $\operatorname{VR}(k)$ is the $\operatorname{VR}$ for the $k$ th difference. $\mathrm{Z}(k)$ is the homoscedastic robust test statistic, and $\mathrm{Z}^{*}(k)$ is the heteroscedastic-robust test statistic. Under the random walk null hypothesis, $\operatorname{VR}(k)=1$, and the return series follows a random walk, where $k$ indicates the number of days, weeks, and months in the base observation interval. The test statistics have a standard normal asymptotic distribution. $* * *, * *$, and $*$ represent significance at the $0.01,0.05$, and 0.10 levels, respectively

heteroscedasticity may be present in the daily stock prices of the securities traded on the SSM. The Z-statistics associated with intervals $k=2,4,8$, and 16 are 7.07, 5.33, 5.83, and 5.47 , respectively. In addition, a close examination of the heteroscedasticity-consistent variance ratio test statistic, $Z^{*}(k)$, indicates that when heteroscedastic disturbances are 
present, the null of the RWH is rejected for all $k$ values at the chosen levels of significance. The findings suggest that the refutation of the RWH for all $k$ intervals under the homoscedastic test statistic is due to the existence of heteroscedasticity and not mean reversion, thereby lending strong support to $\mathrm{H} 2$. The estimates for the weekly and monthly observed returns follow similar patterns, so that the hypothesis that the stock price series is in step with a homoscedastic random walk is firmly rejected, which is in accordance with prior expectations and thus lends support to $\mathrm{H} 2$. Essentially, the above result may originate from either autocorrelation or heteroscedasticity in the stock price series. The results also indicate that the hypothesis of a heteroscedastic random walk is firmly rejected, suggesting that the autocorrelation of weekly and monthly increments in stock prices on the SSM results in the RWH are outright rejected, thus supporting $\mathrm{H} 2$.

Panel B presents the results for the sub-period of 1994-2006, the period before the CMA began shaping corporate governance in Saudi Arabia. The values indicate that the hypothesis that $V R(k)=1$ can be rejected based on the homoscedastic assumption. Further, the variance ratio test also highlights the presence of positive serial correlation in the daily stock prices of the stocks traded on the SSM. Turning to the heteroscedasticity-consistent variance ratio statistic, $Z^{*}(k)$, when heteroscedastic disturbances are under scrutiny, the null hypothesis of a random walk is refuted, which again supports $\mathrm{H} 2$. The Z-statistics for intervals $k=2$ and $k=16$ are 2.03 and 1.78 , respectively, thus leading to rejections at the $5 \%$ and $10 \%$ levels. The variance ratio test also suggests the presence of a positive correlation in daily price series across intervals, since it would be erroneous for the RWH to be rejected because of the reported values, which are biased owing to the presence of heteroscedasticity in the stock price series. We also report the Z-statistics adjusted for this violation of homoscedasticity; however, the results remain the same.

A similar result is attained for the weekly and monthly data. Again, the individual VRs, $V R(k)$ based on weekly and monthly returns are refuted at the selected significance levels, again supporting $\mathrm{H} 2$. For both the weekly and monthly frequencies, the variance ratios are larger than unity, indicating that variances grow more than proportionally with time. For these two data frequencies, from the heteroscedasticity-consistent variance ratio test statistic, $Z^{*}(k)$, the null hypothesis of a random walk is refuted when heteroscedastic disturbances are under consideration for all $k$ values at the chosen levels of significance. Under the homoscedastic test statistic, the results point to the rejection of the RWH for all $k$ intervals due to the presence of heteroscedasticity, further supporting H2. For the weekly stock price series, the Z-statistics associated with intervals $k=2,4,8$, and 16 are 5.77, 5.19, 4.56, and 4.81, respectively, while for the monthly series, the Z-statistics are 3.36, 3.75, 4.74 , and 4.47 , respectively. These findings are expected, particularly since the sample encompasses the stock market crash of 2006, which exposed deep inefficiencies in market operations along with insider trading, share price manipulation, and false statements. These behaviours had the tacit approval of the existing weak regulatory regime and that of Saudi policymakers, thereby helping compound the market inefficiency.

From Panel C, for sub-period 2007-2016, which includes the period of the global financial crisis, the estimates for the daily stock price series indicate we can reject the hypothesis of a random walk for all $k$ intervals. The results strongly suggest that stock prices do not accord with the RWH, since the $V R(k)$ values are significantly different from 1 , and the stocks traded on the SSM have the simultaneous properties of autocorrelation and heteroscedasticity, thereby supporting $\mathrm{H} 2$. Based on the heteroscedasticity-consistent variance ratio test statistic, $Z^{*}(k)$, when heteroscedastic disturbances are considered, the rejection of the null hypothesis of a random walk is confirmed for all $k$ intervals at the selected significance levels. These estimates indicate that the outright rejection of the RWH for all 
$k$ intervals under the homoscedastic test statistic, $Z(k)$, is related to the presence of heteroscedasticity. The Z-statistics for intervals $k=2,4,8$, and 16 are 4.77, 5.03, 3.98, and 3.09 , respectively. Given that these statistics point to the SSM being an informationally inefficient market, it is worth mentioning that the impact of the 2007-2009 financial crisis had a further unsettling effect on the SSM, as it revealed the same inefficiencies in the operation of the market that were present in the period leading to the SSM crash of 2006. These include a trading environment plagued by insider trading, illegal speculation for the stocks of Saudi companies, poor regulatory oversight, and unwillingness of regulators to impose sanctions for market abuse. Further, a lack of transparency and disclosure by listed companies, many of whom failed to disclose their financial statements, prompted policymakers to outline and implement a series of credible policies designed to not only calm the market but also restore investors' confidence at a time when the market was deteriorating more rapidly than in 2006. Specifically, widespread changes were made in market transparency and financial reporting, in addition to giving the CMA enforcement powers, including regulatory powers. With its new powers, the CMA initiated the adoption of International Reporting Standards and fined the companies that failed to provide their reports on time. The CMA also invited foreign investment institutions (and thus, good financial practices such as analysts' recommendations) to invest in the Saudi market and, most importantly, it created the corporate governance codes. These actions were seen by the market as reflecting that policymakers had learnt from the mistakes of 2006 and understood it was necessary to calm the markets and restore investor confidence - which is key for economic recovery, development, and growth - to put in place sustainable measures for improving SSM efficiency.

Further, the results for the weekly and monthly stock price series indicate that the market efficiency level improved, which may account for the impact of the above-mentioned policies, as the variance ratios at various intervals are greater than unity. For both data frequencies, the $Z^{*}(k)$ s are non-significant, suggesting that the ratios are not significantly different from unity, and the null hypothesis of a random walk for all $k$ intervals cannot be refuted. It should also be noted that, for both data frequencies, under the assumption of homoscedasticity, the values suggest we cannot refute the null hypothesis of a random walk for every $k$ interval. The Z-statistics with intervals $k=2,4,8$, and 16 for the weekly data are $0.31,1.04,1.12$, and 0.78 , respectively, while for the monthly data, these are $1.32,0.94$, 0.74 , and -0.28 , respectively.

To further investigate whether stock prices on the SSM follow the RWH, we apply the $M V R$ test of Chow and Denning (1993) to adjust for the bias that may arise from the joint nature of the $V R$ test. $^{2}$ Following Lo and MacKinlay (1988) and Poterba and Summers (1988), the Z-statistics in Panel A of Table 5 are compared with the normal and SMM distribution critical values, as reported in Chow and Denning (1993), for achieving a more accurate estimate of the degree of bias. For all data frequencies, we display values of the multiple variance ratio statistics with homoscedastic, $M V R Z(k)$, and heteroscedastic, $\operatorname{MVRZ}^{*}(k)$, incremental random walks.

At the selected significance level, the homoscedastic and heteroscedastic versions of the test reject the null hypothesis of a random walk for the SSM for the daily, weekly, and monthly stock price series for the full sample period of 1994-2016. The null hypothesis that stocks traded on the SSM follow a homoscedastic random walk is rejected, since

\footnotetext{
${ }^{2}$ Chow and Denning (1993) demonstrate that the asymptotic joint confidence interval needs to be at least $100(1-\alpha) \%$ for a set of $m$ variance ratios $V R\left(k_{i}\right), i=1,2, \ldots m$.
} 
Table 5 Multiple joint variance ratio (MVR) tests

\begin{tabular}{|c|c|}
\hline \multicolumn{2}{|c|}{ Panel A: 1994-2016 } \\
\hline \multicolumn{2}{|l|}{ Daily } \\
\hline $\operatorname{MVRZ}(k)$ & $7.07 * * *$ \\
\hline $\operatorname{MVRZ} *(k)$ & $3.23 * * *$ \\
\hline \multicolumn{2}{|l|}{ Weekly } \\
\hline $\operatorname{MVRZ}(k)$ & $4.17 * * *$ \\
\hline $\operatorname{MVRZ} *(k)$ & $2.44 *$ \\
\hline \multicolumn{2}{|l|}{ Monthly } \\
\hline $\operatorname{MVRZ}(k)$ & $4.21 * * *$ \\
\hline $\operatorname{MVRZ} *(k)$ & $3.15^{* * * *}$ \\
\hline \multicolumn{2}{|c|}{ Panel B: 1994-2006 } \\
\hline \multicolumn{2}{|l|}{ Daily } \\
\hline $\operatorname{MVRZ}(k)$ & $5.05^{* * *}$ \\
\hline $\operatorname{MVRZ} *(k)$ & 2.03 \\
\hline \multicolumn{2}{|l|}{ Weekly } \\
\hline $\operatorname{MVRZ}(k)$ & $5.77 * * *$ \\
\hline $\operatorname{MVRZ} *(k)$ & $2.96 * *$ \\
\hline \multicolumn{2}{|l|}{ Monthly } \\
\hline $\operatorname{MVRZ}(k)$ & $4.74 * * *$ \\
\hline $\operatorname{MVRZ} *(k)$ & $3.37 * * *$ \\
\hline \multicolumn{2}{|c|}{ Panel C: 2007-2016 } \\
\hline \multicolumn{2}{|l|}{ Daily } \\
\hline $\operatorname{MVRZ}(k)$ & $5.03 * * *$ \\
\hline $\operatorname{MVRZ} *(k)$ & $2.57 * *$ \\
\hline \multicolumn{2}{|l|}{ Weekly } \\
\hline $\operatorname{MVRZ}(k)$ & 1.12 \\
\hline $\operatorname{MVRZ} *(k)$ & 0.69 \\
\hline \multicolumn{2}{|l|}{ Monthly } \\
\hline $\operatorname{MVRZ}(k)$ & 1.32 \\
\hline $\operatorname{MVRZ} *(k)$ & 0.90 \\
\hline
\end{tabular}

$\operatorname{MVRZ}(k)$ is the homoscedastic and $\operatorname{MVRZ} *(k)$ the heteroscedasticrobust version of the Chow-Denning test. The 0.05 critical region of the studentised maximum modulus distribution is 2.49 . ***, **, and $*$ indicate rejection of the null hypothesis at the $0.01,0.05$, and 0.10 significance levels, respectively

$\operatorname{MVRZ}(k)$ of $7.07>2.49$. This rejection of the RWH under homoscedasticity may well stem from heteroscedasticity and/or autocorrelation in the stock price series. Notably, the $M V R Z *(k)$ of $3.23>2.49$, thereby refuting the null hypothesis of a heteroscedastic random walk. Similar results are obtained for the weekly and monthly return series. For both stock price series, the homoscedastic and heteroscedastic RWH are rejected owing to the presence of significant positive autocorrelation, which supports $\mathrm{H} 2$.

Table 5, Panel B reports the results for the pre-corporate governance sub-period 1994-2006; for the daily series, the null hypothesis that the stock price series follows a homoscedastic random walk is rejected, since $\operatorname{MVRZ}(k)=5.05$. As $M V R Z^{*}(k)=2.03$, we do not reject the null hypothesis of a heteroscedastic random walk. For the weekly and monthly observed returns, the results follow a similar pattern; that is, the homoscedastic 
Table 6 WALD tests for the daily, weekly, and monthly Saudi stock market returns

\begin{tabular}{lc}
\hline Panel A: 1994-2016 & \\
Daily & $67.75 * * *$ \\
Weekly & $23.83 * * *$ \\
Monthly & $19.67 * * *$ \\
Panel B: 1994-2006 & \\
Daily & $79.50 * * *$ \\
Weekly & $42.69 * * *$ \\
Monthly & $25.49 * * *$ \\
Panel C: 2007-2016 & \\
Daily & $27.09 * * *$ \\
Weekly & 1.96 \\
Monthly & 5.44 \\
\hline
\end{tabular}

The reported WALD test is based on a comparison of the variance ratios of the $2,4,8$, and 16 horizons. $* * *$ represents significance at the 0.01 level

and heteroscedastic RWHs are rejected owing to the presence of positive autocorrelation in the stock price series.

Panel C reports the estimates for sub-period 2007-2016, during which there was a concerted effort by policymakers to implement a series of measures designed to improve the level of corporate governance in Saudi Arabia. The results for the daily return series indicate that, on account of the values of $\operatorname{MVRZ}(k)=5.03$ and $M V R Z *(k)=2.57$, stocks traded on the SSM seem not to subscribe to the RWH. The weekly stock price series indicate that, for the estimates, the null hypothesis that stock prices follow a random walk process is not rejected, since $\operatorname{MVRZ}(k)=1.12$ under homoscedasticity and $M V R Z *(k)=0.69$ under heteroscedasticity. Further, the results for the monthly return series are markedly different from the daily ones but are the same for the weekly stock price series. For the monthly series, $\operatorname{MVRZ}(k)=1.32$ and $M V R Z *(k)=0.90$. Therefore, the RWH is not rejected.

Overall, it can be conjectured that the evidence is strong that stocks traded on the SSM do not follow the hypothesis of random walk, since daily data tend to contain more information than weekly and monthly data. Therefore, it is reasonable to conclude that the SSM is weak-form inefficient. Although, the results from the monthly and weekly data frequencies strongly suggest the market appears to have evolved towards relative efficiency, especially during the post-corporate governance code period, which does affirm $\mathrm{H} 1$. In this case, market capitalisation and liquidity may well have played a role in accounting for this result, not discounting the series of reforms the CMA implemented to ameliorate the operation of the SSM. The dissemination and enforcement of tighter regulations and rules pertaining to SSM management, combined with the emphasis on informational transparency and with information transmission, had a positive effect on SSM efficiency.

Although Chow and Denning's (1993) MVR test eliminates the limitations posed by the individual and $M V R$ tests, it is noteworthy to mention that both tests are predisposed to statistical bias due to the violation of the normality requirements. This is because such parametric tests are likely to lead to a statistical bias from the use of non-normally distributed time series under normality requirements.

For robustness, we apply Richardson and Smith's (1991) WALD test and the runs test on the stock price series for daily, weekly, and monthly data (see Table 6). It is of particular interest to see how Richardson and Smith's WALD test results stand in relation to the 
Table 7 Runs test on the Saudi stock market

\begin{tabular}{|c|c|c|c|c|c|}
\hline & $N$ & $M$ & $\mathrm{E}(M)$ & $\sigma(M)$ & $\mathrm{Z}$ \\
\hline \multicolumn{6}{|c|}{ Panel A: 1994-2016 } \\
\hline Daily & 6296 & 2751 & 3149 & 39.6705 & $-10.0326 * * *$ \\
\hline Weekly & 1145 & 508 & 573.5 & 16.9115 & $-3.8731 * * *$ \\
\hline Monthly & 274 & 122 & 138 & 8.26136 & $-1.93673 *$ \\
\hline \multicolumn{6}{|c|}{ Panel B: 1994-2006 } \\
\hline Daily & 3802 & 1592 & 1902 & 30.8261 & $-10.0564 * * *$ \\
\hline Weekly & 644 & 270 & 323 & 12.6787 & $-4.18023 * * *$ \\
\hline Monthly & 154 & 61 & 78 & 6.18466 & $-2.74874 * * *$ \\
\hline \multicolumn{6}{|c|}{ Panel C: 2007-2016 } \\
\hline Daily & 2493 & 1159 & 1247.5 & 24.96 & $-3.54568 * * *$ \\
\hline Weekly & 500 & 238 & 251 & 11.1692 & -1.16392 \\
\hline Monthly & 119 & 61 & 60.5 & 5.43139 & 0.0920575 \\
\hline
\end{tabular}

$N$ is the number of observations, $M$ is the number of runs, $\mathrm{E}(M)$ is the expected runs computed, $\sigma(M)$ is the standard deviation, and $\mathrm{Z}$ is the Z-statistic. A negative Z-statistic indicates a positive serial correlation and vice versa. $* * *, * *$, and $*$ represent significance at the $0.01,0.05$, and 0.10 levels, respectively

single and $M V R$ test results. For each set of data frequencies reported in Panel A for the entire period, the results indicate that the hypothesis that stocks traded on the SSM follow a random walk is not supported, which corroborates the single and $M V R$ test results and thus affirms H2. Similar to the entire period's results, for the sub-period results in Panel B (1994-2006, or the pre-corporate governance period), the WALD test indicates the outright rejection of the random walk behaviour of stocks traded on the SSM for daily, weekly, and monthly data, thereby confirming $\mathrm{H} 2$.

For the second sub-period (2007-2016, or the post-corporate governance period), the results show that, while the WALD test rejects the RWH for daily data, the hypothesis is supported for the weekly and monthly data frequencies. These results imply a degree of sub-period efficiency improvement and, moreover, the effectiveness of the reforms, including the role played by the SSM in promoting good corporate governance of the listed Saudi companies (including reforms directed at increasing transparency and disclosure rules, as previously noted), which affirms H1. Accordingly, the findings suggest that there is a close relationship between the development of the SSM and the system of corporate governance. As such, the SSM may be considered an effective mechanism for instilling good corporate governance practices among the listed Saudi companies.

It should be noted that the runs test is a non-parametric test, primarily concerned with the randomness of the sequence of price changes in a time series of stock prices. As such, it may be viewed as being either (i) a succession of price changes of the same sign, or (ii) a succession of zero price changes. Therefore, the test results accept the null hypothesis of independence of successive price changes for the stock price series whenever there is a close enough match between the expected and actual number of runs. The significant presence of a large/low number of actual runs compared with the number of expected runs would reject the RWH. Table 7 displays the estimates of the results of the runs test of $M$ and $Z$ for the daily, weekly, and monthly stock price series.

From Panel A, over the entire period (1994-2016), the runs test indicates that the null hypothesis of randomness is refuted for all data frequencies at the selected significance 
levels, since the Z-statistics are -10.0326 for the daily price series, -3.8731 for the weekly series, and -1.93673 for the monthly series, which affirms $\mathrm{H} 2$. These values are higher than the critical ones, indicating an overwhelming rejection of the randomness of data frequencies due to the presence of statistically significant serial correlation.

Considering the first sub-period (1994-2006), the Z-statistics in Panel B indicate that the RWH is refuted, for not only the daily and weekly stock price series but also the monthly returns, which is consistent with the positive serial correlation of returns. This provides evidence against the stock market being characterised as weak-form efficient, thus lending strong support for H2. However, as this is the period prior to the implementation of corporate governance code, it will be interesting to see the impact of the implementation of corporate governance codes on the overall efficiency of the stock market. Thus, the central question that arises here is whether the implementation of a corporate governance code improved the efficiency of the SSM?

Panel C reports the values of the Z-statistics for sub-period 2007-2016, reflecting the effects of the implementation of the Saudi corporate governance code. This indicates a strong rejection of the RWH for the daily stock price series, as the Z-statistic is -3.54568 , which is consistent with the positive serial correlation of returns. With weekly data, the Z-statistic is -1.16392 , which is non-significant. Therefore, the RWH is not rejected for this data frequency, thereby lending support to H1. Additionally, with monthly data, the results show that the Z-statistic is 0.0920575 . Therefore, the RWH is not rejected for monthly data. However, Tables 4-7 display evidence consistent with the literature in rejecting the RWH (see Shiller and Perron 1985; Summers 1986; Poterba and Summers 1988; Lo and MacKinlay 1988; Urrutia 1995; Grieb and Reyes 1999; Abraham et al. 2002; AlKhazali et al. 2007; Hoque et al. 2007). Particularly, the results are consistent with the findings of not only Urrutia (1995), who rejects the null RWH for Latin American emerging markets, but also Al-Khazali et al. (2007) for a group of Middle Eastern stock markets and Hoque et al. (2007) for a group of Asian markets. The results also suggest the common characteristics of emerging markets, which emphasise that prices and returns are negatively serially correlated, with the serial correlation becoming increasingly negative as the interval increases. If such a process governs returns, the VRs should be less than unity for longer horizons. Overall, the empirical evidence does not contradict these implications that the stock price series do not follow the RWH, thus confirming $\mathrm{H} 2$.

The implication is that the inefficiencies in the SSM mean there are profitable opportunities for astute market agents who are perhaps better informed at the expense of less informed investors. Such inefficiency is more likely to result in a large cost to the Saudi government, meaning that the ensuing inefficient allocation of resources must somehow be absorbed, and policymakers must instigate measures to reduce the costs that naturally arise from an inefficient stock market. One way of tackling this inefficiency would be for the CMA to seek improvements to the legal system and continue to reform the Saudi corporate governance system by improving the regulatory framework and increasing the transparency and internal controls of listed corporations. That is, underdeveloped legal, information, and corporate governance systems affect the price discovery process and can be at fault for slowing down the pace at which new information can be incorporated into security prices.

Therefore, the results in Tables 4 and 5 are reinforced when applying the Richardson and Smith WALD test and runs test. One reason is that the SSM pertains to a still developing market, characterised by Group of Seven (G7) standards, low liquidity, investors' trading on less than accurate information, less than adequate disclosures, and non-trivial barriers to entry, such as restrictions on the participation of international investors (which have only recently been removed). The results could also be due to the presence of time-varying 
risk premia. Furthermore, these are nominal returns from an emerging oil dependent economy whose significant price volatility shook the confidence of the market over the analysed period as a result of a series of price adjustments. These adjustments also resulted in reducing market liquidity and may have contributed to a reduction in overall market efficiency. Consequently, the SSM may be considered less efficient than developed G7 stock markets, despite the significant efforts of policymakers to ensure that the technical and organisational aspects of the market environment mimic those of G7 markets. It may also be conjectured from Tables 6 and 7 that, while the RWH is refuted for the full sample and the precorporate governance code period, there are improvements in the overall efficiency of the SSM based on both weekly and monthly data. This improvement in efficiency may partly be explained by the series of reforms that policymakers have embarked upon in recent years to improve the operation of the SSM. During 2007--2016, the enforcement of regulations and laws regarding the management of the market, informational transparency, and information transmission has positively influenced SSM efficiency.

In this respect, most of the improvement in the pricing efficiency of the SSM comes from measures implemented by policymakers as a result of the impact of the 2007-2009 global financial crisis, as well as the participation of non-GCC foreign investors in the market. This change may have reduced the information disadvantage of foreign investors and facilitated a more rapid information diffusion amongst them. Additionally, the regulatory changes may also have resulted in increased domestic investor participation, which could be important from a corporate governance perspective, because the managers of the listed companies characterised by effective and strong governance are expected to be monitored more strictly; they are therefore more inclined to be transparent and less inclined to withhold information. Therefore, we expect listed Saudi companies with better corporate governance levels to have more credible information and for such information to be perceived as being more reliable; see, for example, Bushee and Noe (2000) and Beekes and Brown (2006) for details. In this setting, Diamond (1985) notes that increased information disclosure will have the effect of reducing not only information asymmetry between management and traders, but also traders' motivation for private information acquisition, thereby resulting in reduced heterogeneity among traders' beliefs and a minimal speculative position among informed traders. Moreover, Leuz et al. (2003) posit that effective governance is more likely than not to reduce information asymmetry, while also increasing transparency. In this context, corporate governance mechanisms may be key to explaining the improvements in SSM efficiency and the relevance and effectiveness of corporate governance for listed Saudi companies. As informational problems become more relevant, stricter adherence to corporate governance codes by listed companies should improve the timely release of information, and the information may be perceived as more reliable and have a favourable impact on the timeliness of the price discovery process. That is, relevant private information that would otherwise have been kept private is readily incorporated into publicly observable market prices.

However, the mere presence of corporate governance in a given system and the broadscale acceptance and adherence to its principles do not guarantee economic success but make the process of managing the associated ownership risk more efficient. New information technologies, particularly the trading system, have played an increasingly important role in promoting and improving corporate governance. Interestingly, over all data frequencies, the results show sub-periods of efficiency increases for both the weekly and monthly stock price series during the post-corporate governance period. On an optimistic note, the evidence suggests that, by embracing better governance standards, efficiency increases as a result of the promotion and observance of good corporate governance in listed companies, 
Table 8 Hurst exponent results for daily, weekly, and monthly returns

\begin{tabular}{|c|c|c|c|}
\hline & Hurst exponent & $\begin{array}{l}\text { Hurst } \\
\text { exponent } \\
\text { implies }\end{array}$ & Market decision \\
\hline \multicolumn{4}{|l|}{ Panel A: Daily data } \\
\hline Period: 1994-2016 & 0.9914 & Persistent & Inefficient \\
\hline 1994-2006 & 0.9895 & Persistent & Inefficient \\
\hline $2007-2016$ & 0.9803 & Persistent & Inefficient \\
\hline \multicolumn{4}{|l|}{ Panel B: Weekly data } \\
\hline Period: 1994-2016 & 0.9735 & Persistent & Inefficient \\
\hline 1994-2006 & 0.9835 & Persistent & Inefficient \\
\hline 2007-2016 & 0.9632 & Persistent & Inefficient \\
\hline \multicolumn{4}{|l|}{ Panel C: Monthly data } \\
\hline Period: 1994-2016 & 0.9685 & Persistent & Inefficient \\
\hline 1994-2006 & 0.9623 & Persistent & Inefficient \\
\hline $2007-2016$ & 0.9533 & Persistent & Inefficient \\
\hline
\end{tabular}

along with the observance of other rules related to transparency and improved disclosure. The discipline of listed companies in their observance of good corporate governance practices seems to indicate that to improve the efficiency of the SSM, policymakers should continue to address governance issues, while the SSM should provide incentives for enhanced and better corporate governance for listed companies.

Although the results based on weekly and monthly data indicate improvements in subperiod market efficiency made by improving corporate governance, the situation is more complex. In fact, corporate governance and market efficiency tend to be affected by predetermined factors (e.g. origin of the legal code) and, hence, cannot be easily improved. A comparison with the period prior to the post-corporate governance period shows the SSM to be inefficient and supports H2, while the results in Tables 6 and 7 imply the subperiod efficiency of the SSM in recent years, supporting H1. Particularly, as a financial crisis affects the global stock market, policymakers, the SSM, and investors are likely to devote themselves to enhancing stock market efficiency to mitigate the effects of the crisis. It should be emphasised that the findings also suggest that the SSM needs to particularly work on creating rules, disseminating standards, ensuring the activation of standards, and activating best practices in corporate governance for Saudi listed companies. This includes the creation of positive and best practice models of corporate governance, and the more difficult task of codifying the already created rules; it also involves the elimination of inappropriate behaviours and habits that have been hitherto difficult to eradicate.

\subsection{Hurst Exponent Results}

We deepen the analysis on the efficiency of the SSM by performing the Hurst exponent, calculated by means of the statistical method previously discussed on the logarithm of the daily, weekly, and monthly return series of the SSM, to evaluate the general validity of the results reported in Tables 5 and 6 . The results in Table 8 indicate that the Hurst exponents are well above 0.5 , and for the return series and time periods considered, they suggest that the SSM presents long-range dependence. Moreover, the results indicate that the market is informationally inefficient. All in all, these results provide strong support for $\mathrm{H} 2$. 
More broadly, however, the findings lend support to those of Sadique and Silvapulle (2001) who suggested that the Singapore market presents long-range dependence, indicating that the market is inefficient. In addition, Sensoy (2013) evidenced long-range dependence for MENA stock markets, including the SSM; Al-Shboul and Alsharari (2019) observed features of long-range dependence for the UAE stock markets, and Lamouchi (2020) reported evidence of long memory dependence in the return series of the SSM. These findings would seem to affirm the observation of Grossman and Stiglitz (1980) who showed that perfectly informationally efficient markets are impossible, because some level of inefficiency needs to exist in order to incentivise and reward arbitrageurs to patrol prices and thereby maintain efficiency.

Overall, barring Hurst exponent results and the exception of the first period, the empirical results indicate that the SSM has shifted towards achieving information efficiency, albeit sub-period improvement in market efficiency, and especially since the results under the weekly and monthly return series are consistent with the earlier findings, which confirm sub-period efficiency. Following this line of interpretation, our structural break test would then imply that, over the period evidenced by improvements in Saudi corporate governance arrangements, the SSM is becoming more efficient, on account of the weekly and monthly return series. The test would also imply that the results might be sensitive not only to the return series (Seetharam et al. 2017), but also to the statistical measures employed. This finding is consistent with the assertions of Al-Khazali et al. (2007) and Benjelloun and Squalli (2008).

\subsection{Robustness tests and support for the results}

Other than the clear tangible support for hypothesis H2, the key point of reference in our empirical results (Tables 5 and 6) points to the evidence of sub-period efficiency. The strong positive association evident in the sub-sample provides compelling support for hypothesis H1. We add to such support by considering further analysis regarding the impact of corporate governance change. Specifically, we test the RWH using sectoral (15) data for the SSM (the indices of which were introduced in 2007 following developments in corporate governance) for the period 2007-2016 by performing the MVR test of Chow and Denning (1993). Unlike the single VR test of Lo and MacKinlay (1988), the MVR test does not require the assumption that returns on the stock price indices are normally distributed and allows generalised heteroscedasticity in the return series. Furthermore, the WALD test and Hurst exponent estimation are performed to confirm whether the result is convincing.

The analysis reported in Table 9 contains the MVR statistics with homoscedastic, $\operatorname{MVRZ}(k)$, and heteroscedastic, $M V R Z^{*}(k)$, incremental random walks. At the selected significance level, the homoscedastic and heteroscedastic versions of the test suggest that under the daily series (Panel A) the null of random walk behaviour for all sectors of the SSM is rejected, except for the transport, industrial investment, and retail sectors. For the transport sector, the results show that $\operatorname{MVRZ}^{*}(k)$ is 1.7392 , while for the industrial investment sector, $M V R Z^{*}(k)$ is 1.9022 . Comparable results are obtained for the retail sector, indicating that $M V R Z^{*}(k)$ is 2.0214 . For these sectors, the heteroscedastic RWH is not rejected.

Panel B shows the results under the weekly series. We can assert that the RWH is not rejected for all sectors of the SSM, except for the insurance and petrochemical industries sectors. For the insurance sector, the null of a homoscedastic random walk 
Table 9 MVR test results for daily, weekly, and monthly returns

\begin{tabular}{|c|c|c|}
\hline \multicolumn{2}{|l|}{ Sectors } & \multirow[t]{2}{*}{$\operatorname{Max}|z|$} \\
\hline \multicolumn{2}{|l|}{ Panel A: Daily data } & \\
\hline \multirow[t]{2}{*}{ Agriculture and food industries } & $\operatorname{MVRZ}(k)$ & $4.9713 * * * *$ \\
\hline & $\operatorname{MVRZ}^{*}(k)$ & $2.4870 *$ \\
\hline \multirow[t]{2}{*}{ Building and construction } & $\operatorname{MVRZ}(k)$ & $6.6733 * * *$ \\
\hline & $\operatorname{MVRZ} *(\mathrm{k})$ & $3.4375 * * *$ \\
\hline \multirow[t]{2}{*}{ Banks and financial services } & $\operatorname{MVRZ}(k)$ & $6.2396 * * *$ \\
\hline & $\operatorname{MVRZ} *(\mathrm{k})$ & $3.2908 * * *$ \\
\hline \multirow[t]{2}{*}{ Transport } & $\operatorname{MVRZ}(k)$ & $3.1037 * * *$ \\
\hline & $\operatorname{MVRZ} *(k)$ & 1.7392 \\
\hline \multirow[t]{2}{*}{ Hotel and tourism } & $\operatorname{MVRZ}(k)$ & $4.8348 * * *$ \\
\hline & $\operatorname{MVRZ} *(k)$ & $3.2296 * * *$ \\
\hline \multirow[t]{2}{*}{ Energy and utilities } & $\operatorname{MVRZ}(k)$ & $5.4669 * * *$ \\
\hline & $\operatorname{MVRZ} *(k)$ & $2.9520 * * *$ \\
\hline \multirow[t]{2}{*}{ Insurance } & $\operatorname{MVRZ}(k)$ & $5.8478 * * *$ \\
\hline & $\operatorname{MVRZ} *(k)$ & $3.8319 * * *$ \\
\hline \multirow[t]{2}{*}{ Multi-investment } & $\operatorname{MVRZ}(k)$ & $4.1625 * * *$ \\
\hline & $\operatorname{MVRZ} *(k)$ & $2.4748^{*}$ \\
\hline \multirow[t]{2}{*}{ Real estate development } & $\operatorname{MVRZ}(k)$ & $4.2605 * * *$ \\
\hline & $\operatorname{MVRZ} *(k)$ & $2.4068 *$ \\
\hline \multirow[t]{2}{*}{ Industrial investment } & $\operatorname{MVRZ}(k)$ & $3.4064 * * *$ \\
\hline & $\operatorname{MVRZ} *(k)$ & 1.9022 \\
\hline \multirow[t]{2}{*}{ Media and publishing } & $\operatorname{MVRZ}(k)$ & $9.4006 * * *$ \\
\hline & $\operatorname{MVRZ} *(k)$ & $5.2762 * * *$ \\
\hline \multirow[t]{2}{*}{ Petrochemical industries } & $\operatorname{MVRZ}(k)$ & $4.4134 * * *$ \\
\hline & $\operatorname{MVRZ}^{*}(k)$ & $2.4689 *$ \\
\hline \multirow[t]{2}{*}{ Cement } & $\operatorname{MVRZ}(k)$ & $5.2460 * * *$ \\
\hline & $\operatorname{MVRZ} *(k)$ & $2.8408 * *$ \\
\hline \multirow[t]{2}{*}{ Retail } & $\operatorname{MVRZ}(k)$ & $3.8100 * * *$ \\
\hline & $\operatorname{MVRZ} *(k)$ & 2.0214 \\
\hline \multirow[t]{2}{*}{ Telecommunication and IT } & $\operatorname{MVRZ}(k)$ & $4.4518 * * *$ \\
\hline & $\operatorname{MVRZ}^{*}(k)$ & $2.4284 *$ \\
\hline \multicolumn{3}{|l|}{ Panel B: Weekly Data } \\
\hline \multirow[t]{2}{*}{ Agriculture and food industries } & $\operatorname{MVRZ}(k)$ & 1.9076 \\
\hline & $\operatorname{MVRZ} *(k)$ & 1.2078 \\
\hline \multirow[t]{2}{*}{ Building and construction } & $\operatorname{MVRZ}(k)$ & 0.9278 \\
\hline & $\operatorname{MVRZ} *(k)$ & 0.5308 \\
\hline \multirow[t]{2}{*}{ Banks and financial services } & $\operatorname{MVRZ}(k)$ & 0.6333 \\
\hline & $\operatorname{MVRZ} *(k)$ & 0.4631 \\
\hline \multirow[t]{2}{*}{ Transport } & $\operatorname{MVRZ}(k)$ & 0.9423 \\
\hline & $\operatorname{MVRZ} *(k)$ & 0.7126 \\
\hline \multirow[t]{2}{*}{ Hotel and tourism } & $\operatorname{MVRZ}(k)$ & 0.3727 \\
\hline & $\operatorname{MVRZ} *(k)$ & 0.2768 \\
\hline Energy and utilities & $\operatorname{MVRZ}(k)$ & 1.2096 \\
\hline & $\operatorname{MVRZ}^{*}(k)$ & 1.0482 \\
\hline Insurance & $\operatorname{MVRZ}(k)$ & $3.4845 * * *$ \\
\hline & $\operatorname{MVRZ}^{*}(k)$ & $2.4739 *$ \\
\hline
\end{tabular}


Table 9 (continued)

\begin{tabular}{|c|c|c|}
\hline Sectors & & $\operatorname{Max}|z|$ \\
\hline \multirow[t]{2}{*}{ Multi-investment } & $\operatorname{MVRZ}(k)$ & 0.8351 \\
\hline & $\operatorname{MVRZ}^{*}(k)$ & 0.5963 \\
\hline \multirow[t]{2}{*}{ Real estate development } & $\operatorname{MVRZ}(k)$ & 0.8321 \\
\hline & $\operatorname{MVRZ} *(k)$ & 0.5872 \\
\hline \multirow[t]{2}{*}{ Industrial investment } & $\operatorname{MVRZ}(k)$ & 1.0403 \\
\hline & $\operatorname{MVRZ} *(k)$ & 0.7247 \\
\hline \multirow[t]{2}{*}{ Media and publishing } & $\operatorname{MVRZ}(k)$ & 2.1936 \\
\hline & $\operatorname{MVRZ} *(k)$ & 1.2067 \\
\hline \multirow[t]{2}{*}{ Petrochemical industries } & $\operatorname{MVRZ}(k)$ & $2.2305^{*}$ \\
\hline & $\operatorname{MVRZ} *(k)$ & 1.3362 \\
\hline \multirow[t]{2}{*}{ Cement } & $\operatorname{MVRZ}(k)$ & 1.9325 \\
\hline & $\operatorname{MVRZ} *(k)$ & 1.4564 \\
\hline \multirow[t]{2}{*}{ Retail } & $\operatorname{MVRZ}(k)$ & 0.5810 \\
\hline & $\operatorname{MVRZ} *(k)$ & 0.3698 \\
\hline \multirow[t]{2}{*}{ Telecommunication and IT } & $\operatorname{MVRZ}(k)$ & 0.6666 \\
\hline & $\operatorname{MVRZ} *(k)$ & 0.4531 \\
\hline \multicolumn{3}{|l|}{ Panel C: Monthly Data } \\
\hline \multirow[t]{2}{*}{ Agriculture and food industries } & $\operatorname{MVRZ}(k)$ & 0.7508 \\
\hline & $\operatorname{MVRZ} *(k)$ & 0.7494 \\
\hline \multirow[t]{2}{*}{ Building and construction } & $\operatorname{MVRZ}(k)$ & 1.1547 \\
\hline & $\operatorname{MVRZ}^{*}(k)$ & 0.9207 \\
\hline \multirow[t]{2}{*}{ Banks and financial services } & $\operatorname{MVRZ}(k)$ & 1.0170 \\
\hline & $\operatorname{MVRZ} *(k)$ & 0.8537 \\
\hline \multirow[t]{2}{*}{ Transport } & $\operatorname{MVRZ}(k)$ & 1.7447 \\
\hline & $\operatorname{MVRZ}^{*}(k)$ & 1.7591 \\
\hline \multirow[t]{2}{*}{ Hotel and tourism } & $\operatorname{MVRZ}(k)$ & 0.7937 \\
\hline & $\operatorname{MVRZ}^{*}(k)$ & 0.7526 \\
\hline \multirow[t]{2}{*}{ Energy and utilities } & $\operatorname{MVRZ}(k)$ & 1.7376 \\
\hline & $\operatorname{MVRZ}^{*}(k)$ & 1.6925 \\
\hline \multirow[t]{2}{*}{ Insurance } & $\operatorname{MVRZ}(k)$ & 1.5532 \\
\hline & $\operatorname{MVRZ} *(k)$ & 1.0946 \\
\hline \multirow[t]{2}{*}{ Multi-investment } & $\operatorname{MVRZ}(k)$ & 0.5752 \\
\hline & $\operatorname{MVRZ} *(k)$ & 0.4832 \\
\hline \multirow[t]{2}{*}{ Real estate development } & $\operatorname{MVRZ}(k)$ & 1.3543 \\
\hline & $\operatorname{MVRZ} *(k)$ & 1.2209 \\
\hline \multirow[t]{2}{*}{ Industrial investment } & $\operatorname{MVRZ}(k)$ & 1.2480 \\
\hline & $\operatorname{MVRZ} *(k)$ & 1.1300 \\
\hline \multirow[t]{2}{*}{ Media and publishing } & $\operatorname{MVRZ}(k)$ & 1.9820 \\
\hline & $\operatorname{MVRZ} *(k)$ & 1.5172 \\
\hline \multirow[t]{2}{*}{ Petrochemical industries } & $\operatorname{MVRZ}(k)$ & $2.9820 * *$ \\
\hline & $\operatorname{MVRZ}^{*}(k)$ & 1.7055 \\
\hline \multirow[t]{2}{*}{ Cement } & $\operatorname{MVRZ}(k)$ & 1.6899 \\
\hline & $\operatorname{MVRZ}^{*}(k)$ & 1.4623 \\
\hline \multirow[t]{2}{*}{ Retail } & $\operatorname{MVRZ}(k)$ & 1.5552 \\
\hline & $\operatorname{MVRZ}^{*}(k)$ & 1.5020 \\
\hline
\end{tabular}


Table 9 (continued)

\begin{tabular}{lll}
\hline Sectors & & Max $|z|$ \\
\hline Telecommunication and IT & $\operatorname{MVRZ}(k)$ & 1.0877 \\
& $\operatorname{MVRZ}^{*}(k)$ & 0.9439 \\
\hline
\end{tabular}

$\operatorname{MVRZ}(k)$ is the homoscedastic and $\operatorname{MVRZ}^{*}(\mathrm{k})$ the heteroscedasticrobust version of the Chow-Denning test. The 0.05 critical region of the studentised maximum modulus distribution is 2.49 . ***, **, and $*$ indicate rejection of the null hypothesis at the $0.01,0.05$, and 0.10 significance levels, respectively. The number of daily observations is 2493 , while the number of weekly observations is 500 , and the number of monthly observations is 119

is rejected since $\operatorname{MVRZ}(k)=3.4845>2.49$. Thus, the RWH is rejected either because of heteroscedasticity or autocorrelation in the return series. Parallel results for the subsample analysis in Panel $\mathrm{C}$ indicate that the RWH is not rejected for all sectors of the SSM, except for the petrochemical industries sector. The null hypothesis that the petrochemical industries sector follows a homoscedastic random walk is rejected since $\operatorname{MVRZ}(k)=2.9820>2.49$. This rejection of the RWH under homoscedasticity may again stem from heteroscedasticity and/or autocorrelation in the return series.

The results of the WALD test are presented in Table 10. As reported in Panel A, the WALD test clearly shows that under the daily series the RWH is rejected for all sectors of SSM, which corroborates the MVR test results and thus affirms $\mathrm{H} 2$. Yet, as evidenced in Panel B under the weekly series, the results indicate that the RWH is not rejected for all sectors of the SSM (except insurance and media and publishing). The results in Panel $\mathrm{C}$ under the monthly series are broadly in line with the findings reported in Panel $\mathrm{B}$, except for the insurance, media and publishing, petrochemical industries, and retail sectors.

What makes the greatest impression from the Chow and Denning (MVR) and WALD results reported in Tables 9 and 10, is that for the weekly and monthly return series the evidence in support of market efficiency is particularly strong, except for a few sectors. These results rather suggest that listed firms in the insurance, media and publishing, petrochemical industries, and retail sectors were perhaps slow to comply with the newly imposed governance code, and/or to adhere to various measures that required all listed firms to improve transparency in corporate financial reporting, not least in the quality of financial and other firm-specific information and the speed at which such information became available to market participants. Nonetheless, it needs to be borne in mind that these results are consistent with the results presented in Tables 5 and 6 , which evidence sub-period improvement in SSM efficiency. The results would intimate, moreover, that in general the majority of sectors were compliant with the corporate governance regulations and code of best practices on the need for greater transparency of corporate activities. This points to companies with better corporate governance levels being perceived as reliable processors of information which were ultimately transmitted to the market more quickly and would seem to improve the efficiency of the SSM. These results are, however, in sharp contrast with the finding reported by Squalli (2006) who rejects the RWH for the represented sectors of the UAE stock markets (the ADSE and DFM). The results are nonetheless consistent with the findings of Al-Shboul and Alsharari (2019) who note that the DFM and ADSE evidenced evolving informational efficiency, since both markets were found to be generally inefficient with a trend of improvement towards tweak-form market efficiency. 
Table 10 WALD test results for daily, weekly, and monthly returns

\begin{tabular}{ll}
\hline Sectors & WALD test \\
\hline
\end{tabular}

Panel A: Daily data

Agriculture and food industries

$40.125^{* * *}$

Building and construction

$51.206 * * *$

Banks and financial services

$41.780^{* * *}$

Transport

$12.652 * *$

Hotel and tourism

$24.932 * * *$

Energy and utilities

$31.256^{* * *}$

Insurance

$45.844 * * *$

Multi-investment

$17.982 * * *$

Real estate development

$21.432 * * *$

Industrial investment

Media and publishing

$12.983 * *$

$89.808 * * *$

$20.464 * * *$

Petrochemical industries

$32.562 * * *$

$20.548 * * *$

Retail

$21.941 * * *$

Telecommunication and IT

3.8115

Agriculture and food industries

3.2888

Building and construction

4.0437

Banks and financial services

3.8167

Transport

0.5942

Hotel and tourism

3.6648

Energy and utilities

$17.518 * * *$

Insurance

1.3831

Multi-investment

7.4757

3.9592

Industrial investment

$20.164 * * *$

Media and publishing

Petrochemical industries

5.5884

Cement

4.0715

Retail

1.2140

3.6873

Panel C: Monthly data

Agriculture and food industries

4.2596

Building and construction

Banks and financial services

1.9220

Transport

4.6848

2.9790

Hotel and tourism

4.3531

Energy and utilities

9.1358*

Insurance

0.6007

Multi-investment

2.4044

Real estate development

3.9783

Industrial investment

$15.617 * * *$

Media and publishing

$22.107 * * *$

Cement

3.5816 
Table 10 (continued)

\begin{tabular}{ll}
\hline Sectors & WALD test \\
\hline Retail & $8.0934^{*}$ \\
Telecommunication and IT & 3.2490 \\
\hline
\end{tabular}

The reported WALD test is based on a comparison of the variance ratios of the $2,4,8$, and 16 horizons. $* * * * *$, and $*$ represent significance at the $0.01,0.05$, and 0.10 levels. The number of daily observations is 2493 , while the number of weekly observations is 500, and the number of monthly observations is 119

\section{Conclusions}

This paper examines the efficiency of the SSM and addresses the related research question regarding whether changes in corporate governance matter. For the overall period from 1994-2016 our results indicate that stocks traded on the SSM do not follow the RWH and, therefore, the SSM can be considered generally informationally inefficient, which confirms the early findings of Al-Ghamidi and Opong (1999). A major contribution of this study is the impact of corporate governance change on market efficiency. Estimates based on weekly and monthly returns indicate sub-period improvement in market efficiency, which may be attributed to improvements in the corporate governance arrangements. These improvements enhanced the timelines of the price discovery process, because better governed firms tend to release information on a timely basis that is perceived as more reliable by market participants. This is an important finding, especially in view of policymakers' efforts to establish codes of best practice and the need for listed firms to show greater levels of transparency. Our structural break test indicates one break in 2006 that coincides with the period of corporate governance change, which may well account for sub-period improvement in SSM efficiency. For this reason, we conducted a robustness test for the SSM sector using MVR and WALD analyses in order to confirm our results. The obtained results indicate rejection of the RWH for the overall period (1994-2016), but also show improvements in sub-period efficiency under both weekly and monthly returns. This confirms our earlier findings and would seem to affirm that corporate governance change contributed to improving the environment in which stocks are traded.

Subject to the discussion above, the Hurst exponent estimation indicates strong evidence of long-range dependence and, by implication, suggests that the SSM is an informationally inefficient market, which confirms and completes the above-cited studies for MENA stock markets. The implications of these results are germane to policymakers, regulators, and market participants. Improvements in market efficiency may be related to improvements in corporate governance arrangements, including the institutional structure of the SSM, while the evidence of inefficiency means that investors should be looking for short-term investment opportunities until the market is deemed efficient and thus difficult to predict. Regarding future research, the perspective developed in this study can be used as a template to examine similar issues for other GCC economies that have invested substantially in developing good corporate governance practices, as well as research into how corporate governance characteristics impact on the market reaction to news.

Acknowledgements We thank the editor (Professor. Cheng-Few Lee) and an anonymous reviewer for comments and suggestions that significantly enhanced this work. We would also like to express our thanks to Mubasher for providing the data. The usual disclaimer applies. 


\section{Compliance with ethical standard}

Conflict of interest The authors declare that they have no conflict of interests.

Open Access This article is licensed under a Creative Commons Attribution 4.0 International License, which permits use, sharing, adaptation, distribution and reproduction in any medium or format, as long as you give appropriate credit to the original author(s) and the source, provide a link to the Creative Commons licence, and indicate if changes were made. The images or other third party material in this article are included in the article's Creative Commons licence, unless indicated otherwise in a credit line to the material. If material is not included in the article's Creative Commons licence and your intended use is not permitted by statutory regulation or exceeds the permitted use, you will need to obtain permission directly from the copyright holder. To view a copy of this licence, visit http://creativecommons.org/licenses/by/4.0/.

\section{Appendix 1}

\section{Appendix 1A}

Descriptive Statistics

Normality test for the Hurst exponent

\begin{tabular}{llclll}
\hline Data & Period & Jarque-Bera & Decision & Shapiro-Wilk & Decision \\
\hline Daily & $1994-2016$ & $1170.74 * * *$ & Not-Normal & $0.8866 * * *$ & Not-Normal \\
& $1994-2006$ & $4030.30 * * *$ & Not-Normal & $0.6579 * * *$ & Not-Normal \\
& $2007-2016$ & $143.851 * * *$ & Not-Normal & $0.9531 * * *$ & Not-Normal \\
Weekly & $1994-2016$ & $167.482 * * *$ & Not-Normal & $0.9005 * * *$ & Not-Normal \\
& $1994-2006$ & $631.74 * * *$ & Not-Normal & $0.6650 * * *$ & Not-Normal \\
& $2007-2016$ & $27.8112 * * *$ & Not-Normal & $0.9544 * * *$ & Not-Normal \\
Monthly & $1994-2016$ & $44.3957 * * *$ & Not-Normal & $0.8984 * * *$ & Not-Normal \\
& $1994-2006$ & $151.312 * * *$ & Not-Normal & $0.6651 * * *$ & Not-Normal \\
& $2007-2016$ & $6.7435 * *$ & Not-Normal & $0.9539 * * *$ & Not-Normal \\
\hline
\end{tabular}

$* * *$ and $* *$ represents significance at the $0.01,0.05$ levels

\section{Appendix 1B}

Unit Roots Tests (ADF, PP, KPSS)

\begin{tabular}{|c|c|c|c|c|c|c|c|}
\hline \multirow[t]{2}{*}{ Data } & \multirow{2}{*}{$\begin{array}{l}\text { Sample } \\
\text { period }\end{array}$} & \multicolumn{3}{|l|}{ Level } & \multicolumn{3}{|l|}{ First difference } \\
\hline & & $\mathrm{ADF}$ & PP & KPSS & $\mathrm{ADF}$ & PP & KPSS \\
\hline \multirow[t]{3}{*}{ Daily } & 1994-2016 & -2.143428 & -1.748435 & $0.745006^{* * *}$ & $-15.22880 * * *$ & $-71.89038^{* * *}$ & 0.079262 \\
\hline & 1994-2006 & -1.701300 & -1.645545 & $1.306290 * * *$ & $-10.34638 * * *$ & $-56.52886^{* * *}$ & $0.122421^{*}$ \\
\hline & 2007-2016 & -2.046532 & -1.939418 & $0.482279 * * *$ & $-31.94077^{* * *}$ & $-44.29135^{* * *}$ & 0.065010 \\
\hline \multirow[t]{3}{*}{ Weekly } & 1994-2016 & -2.021897 & -1.890132 & $0.370732 * * *$ & $-17.38769 * * *$ & $-28.13749 * * *$ & 0.065229 \\
\hline & 1994-2006 & -1.694352 & -1.753897 & $0.491406 * * *$ & $-17.61737 * * *$ & $-18.58148^{* * *}$ & 0.106013 \\
\hline & 2007-2016 & -2.489762 & -2.170818 & $0.238705^{* * *}$ & $-10.62270^{* * *}$ & $-21.80813^{* * *}$ & 0.062735 \\
\hline
\end{tabular}




\begin{tabular}{|c|c|c|c|c|c|c|c|}
\hline \multirow[t]{2}{*}{ Data } & \multirow{2}{*}{$\begin{array}{l}\text { Sample } \\
\text { period }\end{array}$} & \multicolumn{3}{|l|}{ Level } & \multicolumn{3}{|l|}{ First difference } \\
\hline & & $\mathrm{ADF}$ & $\mathrm{PP}$ & KPSS & $\mathrm{ADF}$ & PP & KPSS \\
\hline \multirow[t]{3}{*}{ Monthly } & 1994-2016 & -2.079466 & -2.294268 & $0.183324 * *$ & $-9.957823 * * *$ & $-13.58311^{* * *}$ & 0.046016 \\
\hline & 1994-2006 & 2.981594 & -1.980014 & $0.258073 * * *$ & $-6.131436^{* * *}$ & $-8.922511^{* * * *}$ & 0.083325 \\
\hline & 2007-2016 & -2.241936 & -2.306338 & $0.122682 *$ & $-6.340244 * * *$ & $-10.30943^{* * *}$ & 0.054695 \\
\hline
\end{tabular}

ADF is the optimal number of lags chosen according to the Schwarz Information Criterion (SIC) with criterion at its minimum value, provided that the lags yield white-noise residuals. In the Philips Peron test, if the test value is less than the Mackinnon critical value, that means that the variable is non stationary at level (unit root), but if the test value is greater than the Mackinnon critical value, that means the variable is stationary (no unit root). The critical value for ADF and PP used MacKinnon (1996) one-sided $p$-values. In the KPSS test, the test value is greater than the asymptotic critical value, which means that the variable is non stationary at level (unit root), but if the test value is less than the asymptotic critical value, that means the variable is stationary (no unit root). $* * *, * *$ and $*$, represent significance at the $0.01,0.05$, and 0.10 levels, respectively

\section{References}

Abraham A, Seyyed FJ, Alsakran SA (2002) Testing the random walk behavior and efficiency of the Gulf stock markets. Financ Rev 37(3):469-480

Aguilera RV, Cuervo-Cazurra A (2004) Codes of good governance worldwide: what is the trigger? Organ Stud 25(3):415-443

Al-Ajmi J, Kim JH (2012) Are Gulf stock markets efficient? Evidence from new multiple variance ratio tests. Appl Econ 44(14):1737-1747

Alexeev V, Tapon F (2011) Testing weak form efficiency on the Toronto Stock Exchange. J Empir Finance 18(4):661-691

Al-Ghamidi A, Opong K (1999) The behaviour of Saudi stock market prices: some empirical evidence. Int J Bus Stud 7:106-119

Al-Khazali OM, Ding DK, Pyun CS (2007) A new variance ratio test of random walk in emerging markets: a revisit. Financ Rev 42(2):303-317

Al-Shboul M, Alsharari N (2019) The dynamic behavior of evolving efficiency: evidence from the UAE stock markets. Q Rev Econ Finance 73:119-135

Anagnostidis P, Varsakelis C, Emmanouilides CJ (2016) Has the 2008 financial crisis affected stock market efficiency? The case of Eurozone. Phys A 447:116-128

Antoniou A, Ergul N, Holmes P (1997) Market efficiency, thin trading and non-linear behaviour: evidence from an emerging market. Eur Financ Manag 3(2):175-190

Ayadi OF, Pyun CS (1994) An application of variance ratio test to the Korean securities market. J Bank Financ 18(4):643-658

Beekes W, Brown PR (2006) Do better-governed Australian firms make more informative disclosures? J Bus Finance Account 33(3-4):422-450

Benjelloun H, Squalli J (2008) Do general indexes mask sectoral efficiencies? A multiple variance ratio assessment of Middle Eastern equity markets. Int J Manag Finance 4(2):136-151

Borges MR (2010) Efficient market hypothesis in European stock markets. Eur J Finance 16(7):711-726

Broock WA, Scheinkman JA, Dechert WD, LeBaron B (1996) A test for independence based on the correlation dimension. Econom Rev 15(3):197-235

Bushee BJ, Noe CF (2000) Corporate disclosure practices, institutional investors, and stock return volatility. J Account Res 38:171-202

Butler KC, Malaikah SJ (1992) Efficiency and inefficiency in thinly traded stock markets: kuwait and Saudi Arabia. J Bank Finance 16(1):197-210

Chow KV, Denning KC (1993) A simple multiple variance ratio test. J Econom 58(3):385-401

Darrat AF, Zhong M (2000) On testing the random-walk hypothesis: a model-comparison approach. Financ Rev 35(3):105-124

Dedman E (2002) The Cadbury Committee recommendations on corporate governance-a review of compliance and performance impacts. Int J Manag Rev 4(4):335-352

Diamond DW (1985) Optimal release of information by firms. J Finance 40(4):1071-1094 
Dickey DV, Fuller WA (1979) Distribution of the estimators for autoregressive time series with a unit root. J Am Stat Assoc 74(366):427-431

Fama EF (1965) The behavior of stock-market prices. J Bus 38(1):34-105

Fama EF (1970) Efficient capital markets: a review of theory and empirical work. J Finance 25(2):383-417

Fama EF (1991) Efficient capital markets: iI. J. Finance 46(5):1575-1617

Fernández-Rodríguez E, Gómez-Ansón S, Cuervo-García Á (2004) The stock market reaction to the introduction of best practices codes by Spanish firms. Corp Gov 12(1):29-46

Fortune P (1991) Stock market efficiency: An autopsy? New Engl Econ Rev, March/April:17-40

Gozbasi O, Kucukkaplan I, Nazlioglu S (2014) Re-examining the Turkish stock market efficiency: evidence from nonlinear unit root tests. Econ Model 38:381-384

Grieb T, Reyes MG (1999) Random walk tests for Latin American equity indexes and individual firms. J Financ Res 22(4):371-383

Grossman SJ, Stiglitz JE (1980) On the impossibility of informationally efficient markets. Am Econ Rev 70(3):393-408

Hasanov M (2009) Is South Korea's stock market efficient? Evidence from a nonlinear unit root test. Appl Econ Lett 16(2):163-167

Hinich MJ, Serletis A (2007) Episodic nonlinear event detection in the Canadian exchange rate. J Am Stat Assoc 102(477):68-74

Hoque HAAB, Kim JH, Pyun CS (2007) A comparison of variance ratio tests of random walk: a case of Asian emerging stock markets. Int Rev of Econ Financ 16(4):488-502

Karemera D, Ojah K, Cole JA (1999) Random walks and market efficiency tests: evidence from emerging equity markets. Rev Quant Finance Account 13(2):171-188

Kavussanos M, Dockery E (2001) A multivariate test for stock market efficiency: the case of ASE. Appl Financ Econ 11(5):573-579

Kim JH, Shamsuddin A (2008) Are Asian stock markets efficient? Evidence from new multiple variance ratio tests. J Empir Finance 15(3):518-532

Kwiatkowski D, Phillips PCB, Schmidt P, Shin Y (1992) Testing the null hypothesis of stationarity against the alternative of a unit root: how sure are we that economic time series have a unit root? J Econ 54(1-3):159-178

Lamouchi RA (2020) Long memory and stock market efficiency: case of Saudi Arabia. Int J Econ Financ Issues 10(3):29-34

Leuz C, Nanda D, Wysocki PD (2003) Earnings management and investor protection: an international comparison. J Financ Econ 69(3):505-527

Lim KP, Brooks R (2011) The evolution of stock market efficiency over time: a survey of the empirical literature. J Econ Surv 25(1):69-108

Lo AW, MacKinlay AC (1988) Stock market prices do not follow random walks: evidence from a simple specification test. Rev Financ Stud 1(1):41-66

Metghalchi M, Chen C, Hayes LA (2015) History of share prices and market efficiency of the Madrid general stock index. Int Rev Financ Anal 40:178-184

Narayan PK (2005) Are the Australian and New Zealand stock prices nonlinear with a unit root? Appl Econ 37(18):2161-2166

Narayan PK (2008) Do shocks to G7 stock prices have a permanent effect?: evidence from panel unit root tests with structural change. Math Comput Simul 77(4):369-373

Narayan PK, Smyth R (2005) Are OECD stock prices characterized by a random walk? Evidence from sequential trend break and panel data models. Appl Financ Econ 15(8):547-556

Peters EE (1994) Fractal market analysis: applying chaos theory to investment and economics. Wiley, New York

Phillips PCB, Perron P (1988) Testing for a unit root in time series regression. Biometrika 75(2):335-346

Poterba JM, Summers LH (1988) Mean reversion in stock prices: evidence and implications. J Financ Econ 22(1):27-59

Qian XY, Song FT, Zhou WX (2008) Nonlinear behaviour of the Chinese SSEC index with a unit root: evidence from threshold unit root tests. Phys A 387(2-3):503-510

Rejichi IZ, Aloui C (2012) Hurst exponent behavior and assessment of the MENA stock markets efficiency. Res Int Bus Finance 26(3):353-370

Richardson M, Smith T (1991) Tests of financial models in the presence of overlapping observations. Rev Financ Stud 4(2):227-254

Sadique S, Silvapulle P (2001) Long-term memory in stock market returns: international evidence. Int J Finance Econ 6(1):59-67

Samuelson P (1965) Proof that properly anticipated prices fluctuate randomly. Ind Manage Rev 6(2):41-49 
Seetharam Y, Auret C, Celik T (2017) The dynamics of market efficiency: testing the random walk hypothesis in South Africa. Front Finance Econ 14(1):29-69

Sensoy A (2013) Generalized Hurst exponent approach to efficiency in MENA markets. Phys A 392(20):5019-5026

Shiller RJ (1989) Market volatility. The MIT Press, Cambridge

Shiller RJ, Perron P (1985) Testing the random walk hypothesis: power versus frequency of observation. Econ Lett 18(2):381-386

Smith G (2007) Random walks in Middle Eastern stock markets. Appl Financ Econ 17(7):587-596

Squalli J (2006) A non-parametric assessment of weak-form efficiency in the UAE financial markets. Appl Financ Econ 16(18):1365-1373

Stiles P, Taylor B (1993) Benchmarking corporate governance: the impact of the Cadbury Code. Long Range Plann 26(5):61-71

Summers LH (1986) Does the stock market rationally reflect fundamental values? J Finance 41(3):591-601

Tabak BM (2003) The random walk hypothesis and the behaviour of foreign capital portfolio flows: the Brazilian stock market case. Appl Financ Econ 13(5):369-378

Tiwari AK, Kyophilavong P (2014) New evidence from the random walk hypothesis for BRICS stock indices: a wavelet unit root test approach. Econ Model 43:38-41

Urrutia JL (1995) Tests of random walk and market efficiency for Latin American emerging equity markets. J Financ Res 18(1):299-309

Wang Y, Liu L, Gu R (2009) Analysis of efficiency for Shenzhen stock market based on multifractal detrended fluctuation analysis. Int Rev Financ Anal 18(5):271-276

Wright JH (2000) Alternative variance-ratio tests using ranks and signs. J Bus Econ Stat 18(1):1-9

Zattoni A, Cuomo F (2008) Why adopt codes of good governance? A comparison of institutional and efficiency perspectives. Corp Gov 16(1):1-15

Zunino L, Zanin M, Tabak BM, Pérez DG, Rosso OA (2009) Forbidden patterns, permutation entropy and stock market inefficiency. Phys A 388(14):2854-2864

Publisher's Note Springer Nature remains neutral with regard to jurisdictional claims in published maps and institutional affiliations. 